Prepared for the U.S. Department of Energy

under Contract DE-AC05-76RL01830

\title{
Predictive Engineering Tools for Injection-Molded Long-Carbon-Fiber Thermoplastic Composites
}

\author{
Ba Nghiep Nguyen \\ Jin Wang Xiaoshi Jin \\ Umesh N. Gandhi \\ Leonard S. Fifield \\ Franco Costa \\ Steven Mori \\ Seth A. Kijewski \\ Charles L. Tucker III \\ Michael D. Sangid \\ Raj N. Mathur
}

January 2015

Pacific Northwest

NATIONAL LABORATORY

Proudly Operated by Battelle Since 1965 


\title{
DISCI.AIMER
}

This reporl was prepared as an account of work sponsored by an agency of the United States Government. Neither the United States (jovernment nor any agency thereof, nor Battelle Memorial Institute, nor any of their employees makes any warranty, express or implied, or assumes any Iegal liability or responsibility for the accuracy, completeness, or usefulness of any information, apparatus, product, or process disclosed, or represents that its use would not infringe privately awned rights. Relerence herein to any specilic commercial produci, process. or service by trade name, trademark. manufacturer, or otherwise does not necessarily constitule or imply its endorsement, reconmendation, or lavoning by the United States Government or any agency thereof, or Battelle Memorial Institute. The views and opinions of authors expressed herein do not necessarily state or rellect those of the Inited States Government or any agency thereofl"

\author{
PACIFIC NORTHWFST NATIONAI I ABORATORY \\ operated by \\ BAI"IELLE \\ for the \\ INITFD STATES DFPARTMFNT OF FNFRGY \\ under contract DH:-4(0)5-76RLO1\%30 \\ Printed in the United States of America \\ Available to DOE and DOE contractors from the \\ Office of Scientific and Technical Information. \\ P.O. Box 62, Oak Ridge. TN 37831-0062; \\ ph: (865) $576-8401$ \\ fax: $(865) 576-5728$ \\ email: reports âadonis.osti.gov \\ Available to the public from the National Technical Information Service, \\ U.S. Department of Commerce, 5285 Port Royal Rd.. Springfiekd, VA 22161 \\ ph: (800) 553-6847 \\ fax: (703) 605-6900 \\ email: orders@ntis.fedworld.gov \\ online ordering: http://www.ntis.gov/ordering.htm
}

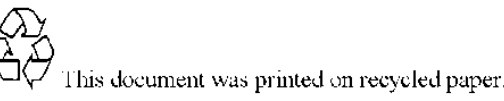

(9.2003) 


\section{Predictive Engineering Tools for Injection-molded Long-Carbon-Fiber Thermoplastic Composites}

\section{Ba Nghiep Nguyen, Leonard S. Fifield}

Pacific Northwest National Laboratory, Richland, WA 99352

Seth A. Kijewski, Michael D. Sangid

Purdue University, West Lafayette, IN 47907

\section{Jin Wang, Xiaoshi Jin, Franco Costa}

Autodesk, Inc., Ithaca, NY 14850

Charles L. Tucker III

University of Illinois at Urbana-Champaign, Urbana, IL 61801

Raj N. Mathur

PlastiComp, Inc., Winona, MN 55987

\section{Umesh N. Gandhi}

Toyota Research Institute North America, Ann Arbor, MI 48105

Steven Mori

MAGNA Exteriors and Interiors Corp., Aurora, Ontario, Canada

Project period: From October 1st 2012 to September 30th, 2016

Reporting period end date: December $31^{\text {st }}$, 2014

Quarterly report submitted to Aaron Yocum, National Energy Technology Laboratory, Morgantown, WV 26507

January 2015

Prepared for the U.S. Department of Energy under Contract DE-AC0576RL01830, Pacific Northwest National Laboratory, Richland, Washington 99352 



\section{Objective}

The objective of this project is to advance the predictive engineering (PE) tool to accurately predict fiber orientation and length distributions in injection-molded long-carbon fiber thermoplastic composites for optimum design of automotive structures using these materials to meet weight and cost reduction requirements defined in Table 2 of DE-FOA-0000648 (Area of Interest 1).

\section{Background}

This project proposes to integrate, optimize and validate the fiber orientation and length distribution models previously developed and implemented in the Autodesk Simulation Moldflow Insight (ASMI) package for injection-molded long-carbon-fiber thermoplastic composites. In our previous US Department of Energy (DOE) funded project entitled: "Engineering Property Prediction Tools for Tailored Polymer Composite Structures" Pacific Northwest National Laboratory (PNNL), with the University of Illinois and Autodesk, Inc., developed a unique assembly of computational algorithms providing state-of-the-art process and constitutive models that enhance the capabilities of commercial software packages to predict fiber orientation and length distributions as well as subsequent mechanical properties of injection-molded long-fiber thermoplastic (LFT) composites. These predictive capabilities were validated using data generated at Oak Ridge National Laboratory on two-dimensional (2-D) structures of edge-gated plaques or center-gated disks injection-molded from long-glassfiber/polypropylene (PP) or long-glass-fiber/polyamide 6,6 (PA66) pellets. The present effort aims at rendering the developed models more robust and efficient to automotive industry part design to achieve weight savings and cost reduction. This ultimate goal will be achieved by optimizing the developed models, improving and integrating their implementations in ASMI, and validating them for a complex three-dimensional (3D) long-carbon fiber (LCF) thermoplastic automotive part. Both PP and PA66 are used for the resin matrices. Local fiber orientation and length distributions at the key regions on the part are measured for the model validation based on the $15 \%$ accuracy criterion. The project outcome will be the ASMI package enhanced with computational capabilities to accurately predict fiber orientation and length distributions in automotive parts designed with long-carbon fiber thermoplastics.

\section{Accomplishments}

During the first quarter of FY 2015, the following technical progress has been made toward project milestones:

1) Autodesk delivered a new research version of ASMI to PNNL. This version includes the improved 3D fiber orientation solver, and the reduced order model (ROM) for fiber length distribution using the proper orthogonal decomposition (POD) implemented in the mid-plane, dual-domain and 3D solvers.

2) Autodesk coordinated a conference paper with PNNL reporting ASMI mid-plane fiber orientation predictions compared with the measured data for two PlastiComp plaques. This paper was accepted for presentation at the 2015 Society for Plastics Engineers (SPE) ANTEC conference (http://www.4spe.org/Events/event.aspx?EventID=51212).

3) The University of Illinois (Prof. Tucker) assisted team members from Purdue with fiber orientation measurement techniques, including interpretation of off-axis cross sections.

4) The University of Illinois assisted Autodesk team members with software implementation of the POD approach for fiber length modeling, and with fiber orientation modeling.

5) The University of Illinois co-authored in the SPE ANTEC paper, participated with the team in discussions of plaque data and model results, and participated in the definition of go/no-go experiments and data. 
6) Purdue University (Purdue) conducted fiber orientation measurements for 3 PlastiComp plaques: fast-fill 30wt\% LCF/PP center-gated, fast-fill 50wt\% LCF/PA66 edge-gated and fast-fill 50wt\% LCF/PA66 center-gated plaques, and delivered the fiber orientation data for these plaques at the selected locations (named A, B, and C) to PNNL. However, the data for the fast-fill 50wt\% LCF/PA66 edge-gated plaque exhibited unusual variations and could not be used for the model validation. Purdue will re-measure fiber orientation for this plaque.

7) Based on discussions with the University of Illinois Purdue explained the ambiguity in the measurements of the fiber orientation components $A_{12}$ and $A_{23}$.

8) PNNL discussed with team members to establish a go/no-go decision plan for the project and submitted the established plan to DOE.

9) PNNL developed a method to recover intact carbon fibers from LCF/PP materials. Samples of fibers recovered were shipped to Purdue for length distribution analysis.

10) PNNL performed ASMI mid-plane analyses for the fast-fill center-gated 30wt\% LCF/PP and $50 \mathrm{wt} \% \mathrm{LCF} / \mathrm{PA} 66$ plaques and compared the predicted fiber orientations with the measured data provided by Purdue at Locations A, B, and C (Figure 1) on these plaques.

11) Based on discussions with the University of Illinois and Autodesk, PNNL proposed a procedure to adjust fiber orientation data for Location A of the center-gated plaques so that the data can be expressed and interpreted in the flow/cross-flow direction coordinate system.

12) PNNL tested the new ASMI version received from Autodesk, examined and discussed 3D fiber orientation predictions for PlastiComp plaques.

13) PlastiComp, Inc. (PlastiComp), Toyota Research Institute North America (Toyota) and Magna Exteriors and Interiors Corp. (Magna) participated in discussions with team members on the go/no-go plan and the issues related to fiber length measurements. Toyota continued the discussion with Magna on tool modification for molding the complex part in order to achieve the target fiber length in the part.

\section{Progress and Status}

\subsection{Fiber Orientation Measurements(Purdue)}

Purdue reported the details of its fiber orientation measurement method developed in FY 2014. Previous measurements were taken from the plaques at Locations $\mathrm{A}, \mathrm{B}$ and $\mathrm{C}$ along the bottom of the horizontal line, as shown Figure 1.

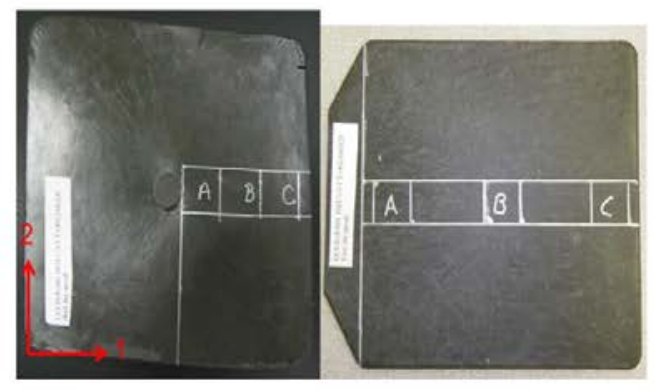

(a)

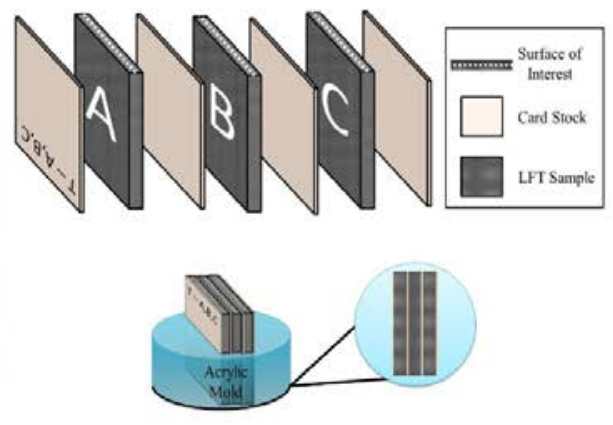

(b)

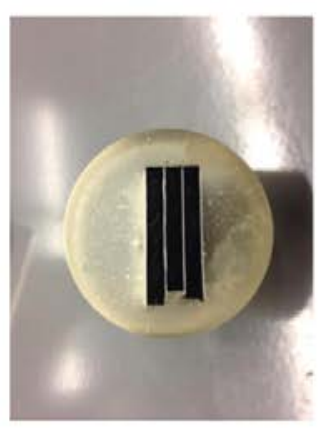

(c)

Figure 1. (a) Locations $\mathrm{A}, \mathrm{B}$ and $\mathrm{C}$ defined on the center-gated and edge-gated plaques where samples were cut out for fiber orientation and length measurements, (b) An illustration of how the three locations are separated and placed in the acrylic, and (c) Image of the real samples mounted in acrylic (top view). 
The coordinate system used to report measured fiber orientation in our study is such that the 1-direction is the flow direction, the 3-direction is the thickness direction and the other normal is the 2-direction. Purdue measured fiber orientation based on the methods reported in References [1-3]. The measurement procedure acquires images of the polished cross-sections where the carbon fibers are detected as ellipses and the resulting images are analyzed. By measuring the ellipticity of these digital images, the fiber orientation can be determined. The orientation of each fiber with respect to a coordinate system is measured as a set of Eulerian angles $\theta$ and $\phi$ by a series of steps. The images undergo a thresholding to contrast each pixel as belonging to either a fiber or the matrix. An edge detection algorithm identifies a set of pixels as an ellipse of a single fiber, and the major and minor axes are calculated. Based on the measured, major axis, $M$; minor axis, $m$; height in the 2-direction, $Y=y_{2}-y_{1}$, and width in the 1direction, $X=x_{2}-x_{1}$ the angles $\theta$ and $\phi$ defining the orientation are calculated and their average results in the orientation tensor components, $A_{i j}^{\prime}$ [2-3]. Next, to account for the original coordinate system used by Bay and Tucker [2-3] being different from the one used in the current study, a rotation tensor, $\mathbf{Q}$ as specified by Phelp [4] was applied to the fiber orientation tensor:

$$
\mathbf{A}=\mathbf{Q} \cdot \mathbf{A}^{\prime} \cdot \mathbf{Q}
$$

where

$$
\begin{aligned}
& \mathbf{Q}=\left(\begin{array}{ccc}
1 & 0 & 0 \\
0 & 0 & 1 \\
0 & -1 & 0
\end{array}\right) \\
& A_{i j}=\left\langle p_{i} p_{j}\right\rangle=\left[\begin{array}{ccc}
\left\langle X^{2}\left(\frac{1}{M^{2}}-\frac{m^{2}}{M^{4}}\right)\right\rangle & \left\langle X Y\left(\frac{1}{M^{2}}-\frac{m^{2}}{M^{4}}\right)\right\rangle & \left\langle X \sqrt{\frac{m^{2}}{M^{4}}-\frac{m^{4}}{M^{6}}}\right) \\
\left\langle X Y\left(\frac{1}{M^{2}}-\frac{m^{2}}{M^{4}}\right)\right\rangle & \left\langle Y^{2}\left(\frac{1}{M^{2}}-\frac{m^{2}}{M^{4}}\right)\right\rangle & \left\langle Y \sqrt{\frac{m^{2}}{M^{4}}-\frac{m^{4}}{M^{6}}}\right) \\
\left\langle X \sqrt{\frac{m^{2}}{M^{4}}-\frac{m^{4}}{M^{6}}}\right\rangle & \left\langle Y \sqrt{\frac{m^{2}}{M^{4}}-\frac{m^{4}}{M^{6}}}\right\rangle & \left\langle\frac{m^{2}}{M^{2}}\right\rangle
\end{array}\right]
\end{aligned}
$$

There is an ambiguity with the components $A_{12}$ and $A_{23}$ of the tensor $A_{i j}$ given in Eq. (3). In terms of the equations that we have followed, the issue is that the choice of which end of the fiber is $\left(x_{1}, y_{1}\right)$ and which end is $\left(x_{2}, y_{2}\right)$ is arbitrary. This means that the values $X=x_{2}-x_{1}$ and $Y=y_{2}-y_{1}$ have a welldefined magnitude, but arbitrary sign. However, if we swap the "1" and "2" ends of the ellipse then both $X$ and $Y$ change sign. The major axis length, $M$, and the minor axis length, $m$, are always positive numbers. Examining the formula for the components of $A_{i j}$, we see that swapping $(X, Y)$ for $(-X,-Y)$ does not affect any component that contains $X^{2}, Y^{2}$ or $X Y$. However, the swap does affect components that contain only $X$ or only $Y$. Thus, choosing one end of the major axis as the $\left(x_{1}, y_{1}\right)$ point versus the other end of the major axis does not affect the diagonal components of orientation, nor does it affect $A_{13}=A_{31}$ (for a 1-3 
section plane). The choice does determine the sign of $A_{12}=A_{21}$ and $A_{23}=A_{32}$ for that ellipse. These are the ambiguous components of the orientation tensor in this type of measurement.

Prof. Tucker pointed to a simple example: we imagine that we had a sample with perfectly aligned fibers, sectioned at 45 degrees to the fiber direction (Figure 2). We would easily compute the diagonal tensor components of $0.5,0$, and 0.5 , but we would not know whether we were looking at all of the fibers at +45 degrees to the plane, all of the fibers at -45 degrees, or some mix of fiber orientations. Given this ambiguity, the best way to report the data for these tensor components is to report the bounding values. To do this, we replace $X$ and $Y$ by their absolute values. This will not affect the unambiguous components, but it will give the maximum algebraic value of the ambiguous components that is consistent with the measurement (an upper bound). The minimum algebraic values (lower bound) are simply the same values with the sign changed. The true values for the sample can lie anywhere between the bounds, but there is no way to specify them more closely based on the measurement alone.
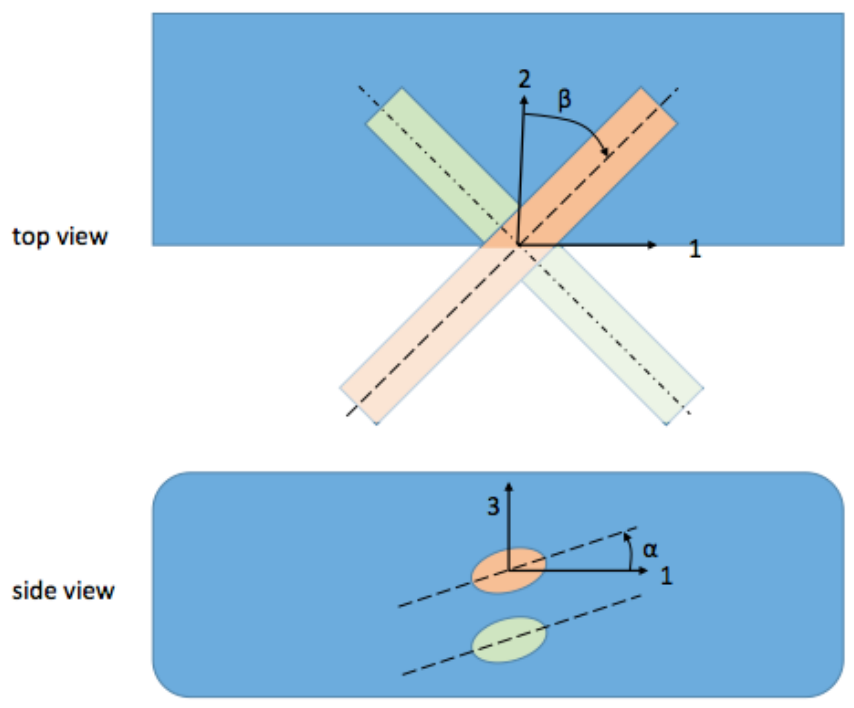

Figure 2. Schematic picture illustrating the ambiguity obtaining the component $A_{12}$ and $A_{23}$ of the orientation tensor.

Based on the discussion with Prof. Tucker, we will specify an upper and lower bound according the equations as follows:

Upper bound:

$$
A_{i j}=\left\langle p_{i} p_{j}\right\rangle=\left[\begin{array}{ccc}
\left\langle\sin ^{2} \theta \cos ^{2} \phi\right\rangle & \langle\sin \theta \cos \theta \cos \phi \mid\rangle & \left\langle\sin ^{2} \theta \cos \phi \sin \phi\right\rangle \\
\langle\sin \theta \cos \theta \cos \phi\rangle & \left\langle\cos ^{2} \theta\right\rangle & \langle\sin \theta \cos \theta \sin \phi \mid\rangle \\
\left\langle\sin ^{2} \theta \cos \phi \sin \phi\right\rangle & \langle\sin \theta \cos \theta \sin \phi\rangle\rangle & \left\langle\sin ^{2} \theta \sin ^{2} \phi\right\rangle
\end{array}\right]
$$

Lower bound: 


$$
A_{i j}=\left\langle p_{i} p_{j}\right\rangle=\left[\begin{array}{ccc}
\left\langle\sin ^{2} \theta \cos ^{2} \phi\right\rangle & \langle-|\sin \theta \cos \theta \cos \phi|\rangle & \left\langle\sin ^{2} \theta \cos \phi \sin \phi\right\rangle \\
\langle-|\sin \theta \cos \theta \cos \phi|\rangle & \left\langle\cos ^{2} \theta\right\rangle & \langle-|\sin \theta \cos \theta \sin \phi|\rangle \\
\left\langle\sin ^{2} \theta \cos \phi \sin \phi\right\rangle & \langle-|\sin \theta \cos \theta \sin \phi|\rangle & \left\langle\sin ^{2} \theta \sin ^{2} \phi\right\rangle
\end{array}\right]
$$

This bounding allows a more complete description of the orientation tensor with respect to rotation from a reference plane. This is needed as the orientation measurements are taken from the bottom surfaces of the samples (illustrated in Figure 3 for a center-gated plaque) since this is the reference cut to extract the samples from the plaques. Since the measurement surface is not parallel to the flow direction, this creates some bias, especially in location A of the center-gated plaque, whose measurement surface deviates about $\sim 25.5$ degree with respect to the flow direction. Thus, by delivering a bound of the orientation tensor, we can account for this bias through a rotation operation of the orientation tensor. It is noted that the misalignment between the flow direction and measurement surface becomes smaller and smaller along the downstream positions from Location A to Location C.

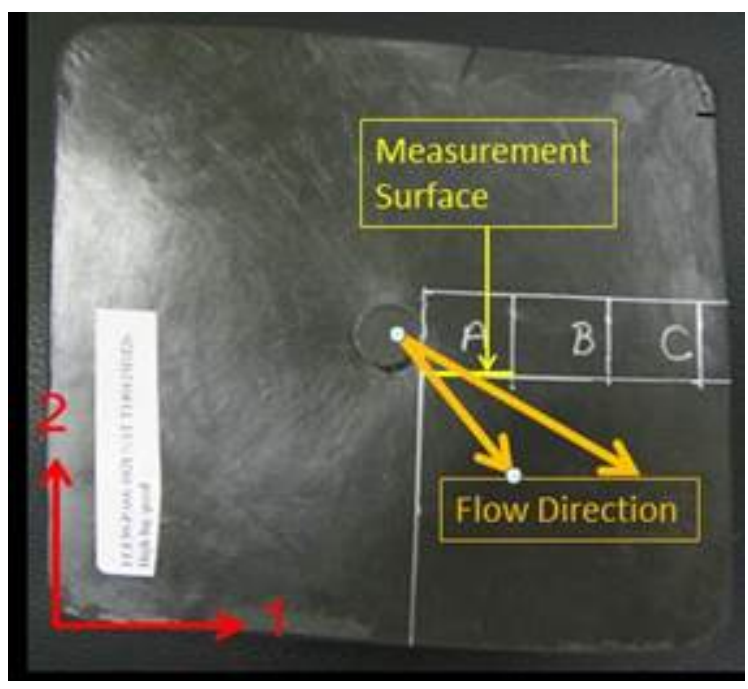

Figure 3. Misalignment between the flow-direction and the measurement surfaces in a center-gated plaque.

For the go/no-go decision, the following are the list of fiber orientation measurements and their status. For the center-gated plaques, Location A will be recut about the center line (representing a radial line from the gate), these locations are awaiting refine measurement as indicated below.

* Fast-fill 30wt\% LCF/PP edge-gated plaque (completed)

* Slow-fill 50wt\% LCF/PP edge-gated plaque (completed)

* Slow-fill 50wt\% LCF/PP center-gated plaque (completed)

* Fast-fill 30wt\% LCF/PP center-gated plaque (completed, awaiting refine data for Location A)

* Fast-fill 50wt\% LCF/PA66 edge-gated plaque (data could not be used, re-measured data were requested)

* Fast-fill 50wt\% LCF/PA66 center-gated plaque (completed, awaiting refine data for Location A) 


\subsection{Fibers Separation for Length Measurement (PNNL)}

PNNL developed a method to recover intact carbon fibers from long carbon fiber injection molded polypropylene composites for fiber length distribution measurement. In previous attempts to recover carbon fibers from polypropylene and from PA6,6 composites through heating of the composites in air (burn-off) it was observed that the diameters of recovered fibers ( $\sim 5$ microns) decreased relative to asmolded diameters ( 7 microns) and that fiber ends were sharpened. These observations are consistent with oxidative damage to the fibers during the heating process for resin removal. The fact that measured fiber lengths were shorter than anticipated was also hypothesized to be due to oxidative damage, resulting in fiber embrittlement and breakage during recovery. To avoid oxidative damage and recover fiber samples with length distributions representative of those in the molded composite an inert atmosphere heating process was developed for resin removal. The process consists of heating the long carbon fiber injection molded polypropylene composite sample in argon at $500^{\circ} \mathrm{C}$ for 2 hours. Microscopic evaluation of the resultant fibers confirmed that the fiber diameter was maintained, that no fiber end sharpening was present, and that the resin was cleanly removed. Residual fiber mass further confirmed the complete extent of resin removal with the process. It was observed that the inert atmosphere burn-off process does not result in complete removal of PA6,6 as evidence by 2-3 wt\% residual mass in addition to fiber mass in the recovered samples and by visible microscopic residue on the fibers. Alternative methods for fiber recovery from PA6,6 composites are under investigation and will be described in a future report.

A small, representative sample of fibers for fiber length distribution measurement is recovered from the fiber mat resulting from inert gas resin burn-off of polypropylene in a process known as down selection or down sampling. The down selection process consists of injecting a column of epoxy resin through the center of the recovered fiber form, separating the cured epoxy plug with captured fibers from surrounding fibers, and burning off (calcining) the epoxy resin to recover the down selected fibers. Fibers were down selected at PNNL from recovered polypropylene purge material (from PlastiComp) fibers and from fiber mats recovered from injection molded plaque coupons. Recovered down selected fiber samples, representative of the fiber length distribution present in each composite at the location of down selection, were shipped to Purdue for fiber dispersion, imaging and fiber length distribution analysis. Table 1 provides a summary of mass loss of the purge materials from PlastiComp's slow-fill 30wt\% LCF/PP edge-gated and center-gated injection moldings. Figures 4 to 9 illustrate the details of the fiber recovery procedure applied to these purge materials to separate carbon fibers from the PP resin for fiber length analysis.

\begin{tabular}{|c|c|c|c|c|}
\hline Sample & $\begin{array}{c}\text { Sample } \\
\text { weight (g) }\end{array}$ & $\begin{array}{c}\text { After calcination } \\
\left(500^{\circ} \mathrm{C}\right) \\
\end{array}$ & $\begin{array}{l}\text { Carbon fiber } \\
\text { content (\%) } \\
\end{array}$ & $\begin{array}{c}\text { Carbon fines } \\
\text { content (\%) }\end{array}$ \\
\hline $\begin{array}{c}\text { Slow-fill 30wt } \% \text { LCF/PP } \\
\text { edge-gated (1) }\end{array}$ & 0.7508 & 0.2154 & 28.69 & 10.03 \\
\hline $\begin{array}{c}\text { Slow-fill 30wt\% LCF/PP } \\
\text { edge-gated (2) }\end{array}$ & 0.8851 & 0.2666 & 30.12 & 6.53 \\
\hline $\begin{array}{c}\text { Slow-fill 30wt } \% \text { LCF/PP } \\
\text { center-gated (1) }\end{array}$ & 1.7906 & 0.5934 & 33.14 & 5.59 \\
\hline $\begin{array}{c}\text { Slow-fill 30wt\% LCF/PP } \\
\text { center-gated (2) }\end{array}$ & 2.6235 & 0.8350 & 32.07 & 5.97 \\
\hline
\end{tabular}

Table 1. Summary of mass loss of purge material from PlastiComp. 

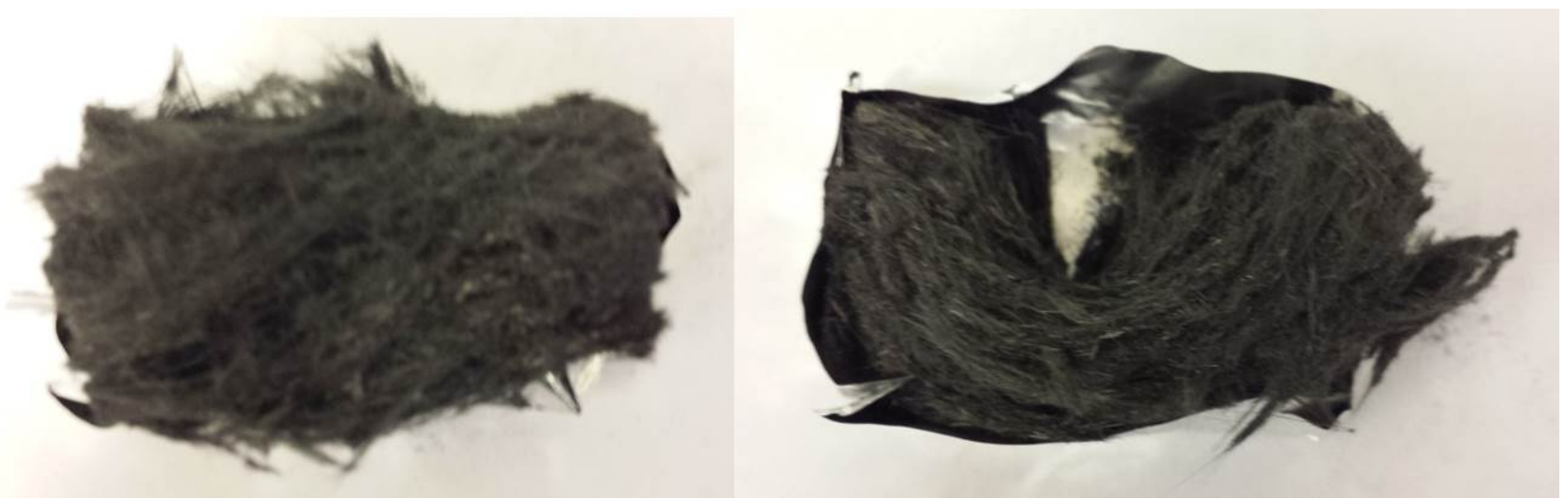

Figure 4. Purge materials (from the slow-fill $30 \mathrm{wt} \% \mathrm{LCF} / \mathrm{PP}$ center gated injection molding) after $500^{\circ} \mathrm{C}$ in argon for 2 hours.
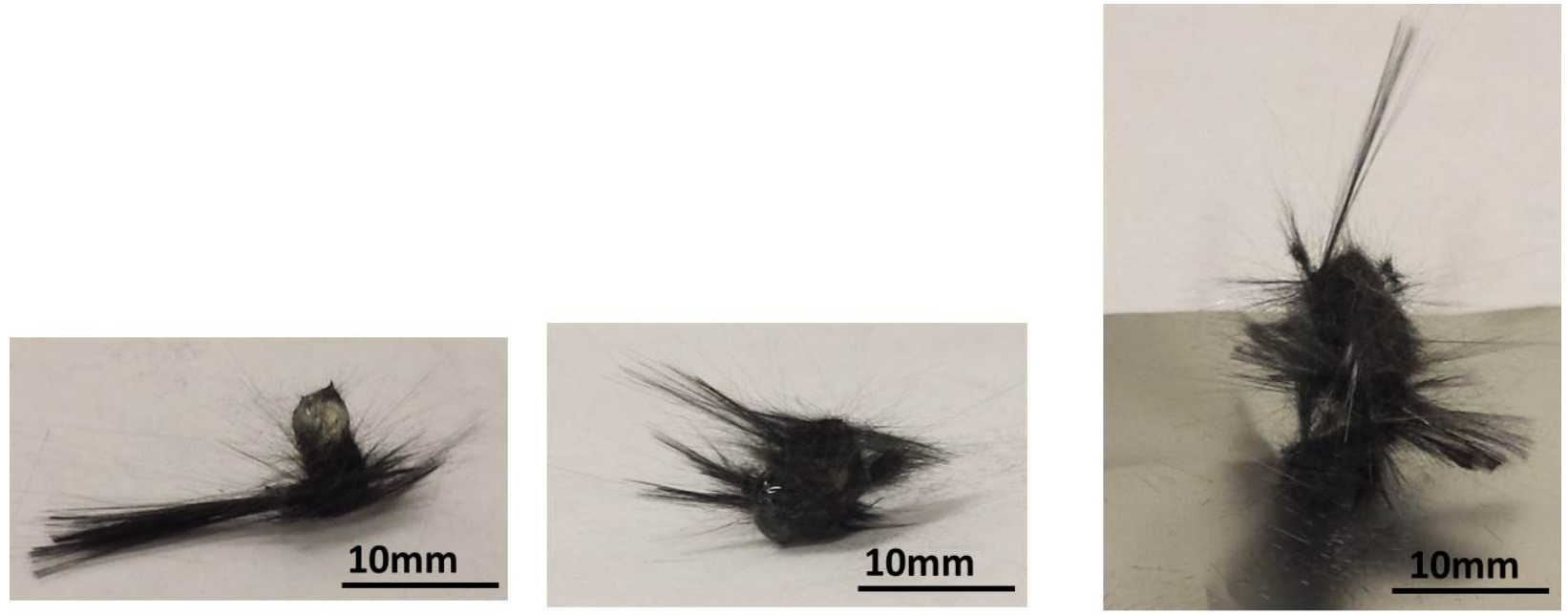

Figure 5. Down-selected fibers with epoxy plugs from purge materials from the slow-fill 30wt\% LCF/PP center gated injection molding.
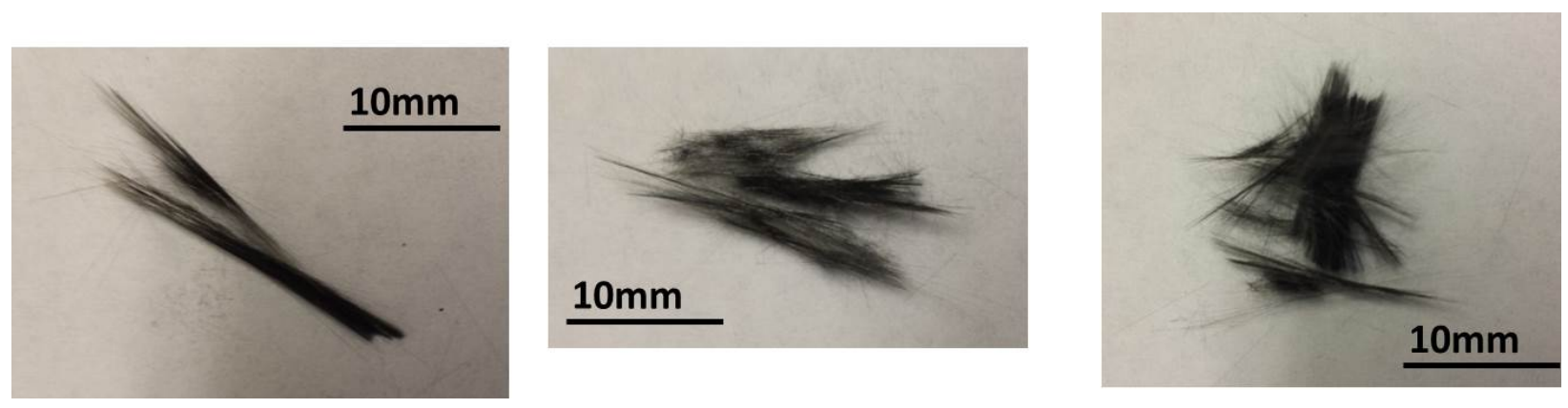

Figure 6. Fibers recovered from down selected fibers with epoxy plugs for length analysis (slow-fill 30wt\% LCF/PP center gated injection molding). 

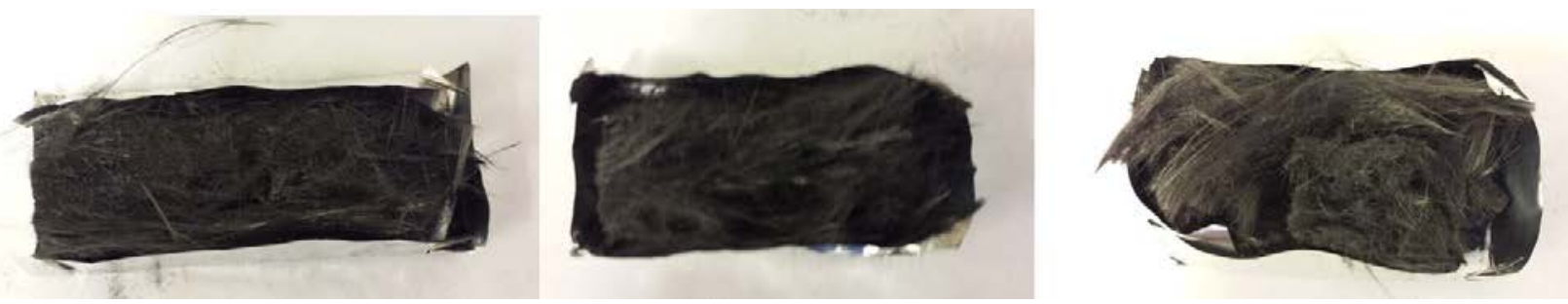

Figure 7. Purge materials (from the slow-fill $30 \mathrm{wt} \% \mathrm{LCF} / \mathrm{PP}$ edge-gated injection molding) after $500^{\circ} \mathrm{C}$ in argon for 2 hours.
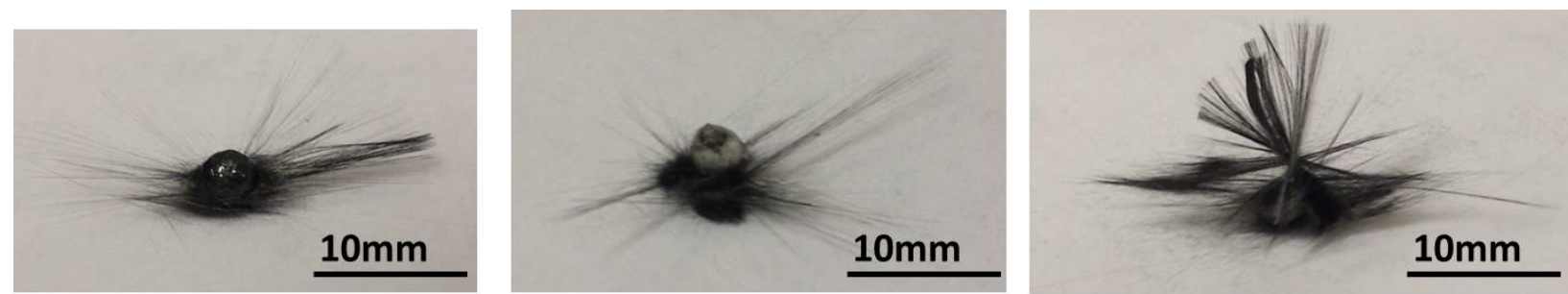

Figure 8. Down-selected fibers with epoxy plugs from purge materials from the slow-fill 30wt\% LCF/PP edge-gated injection molding.
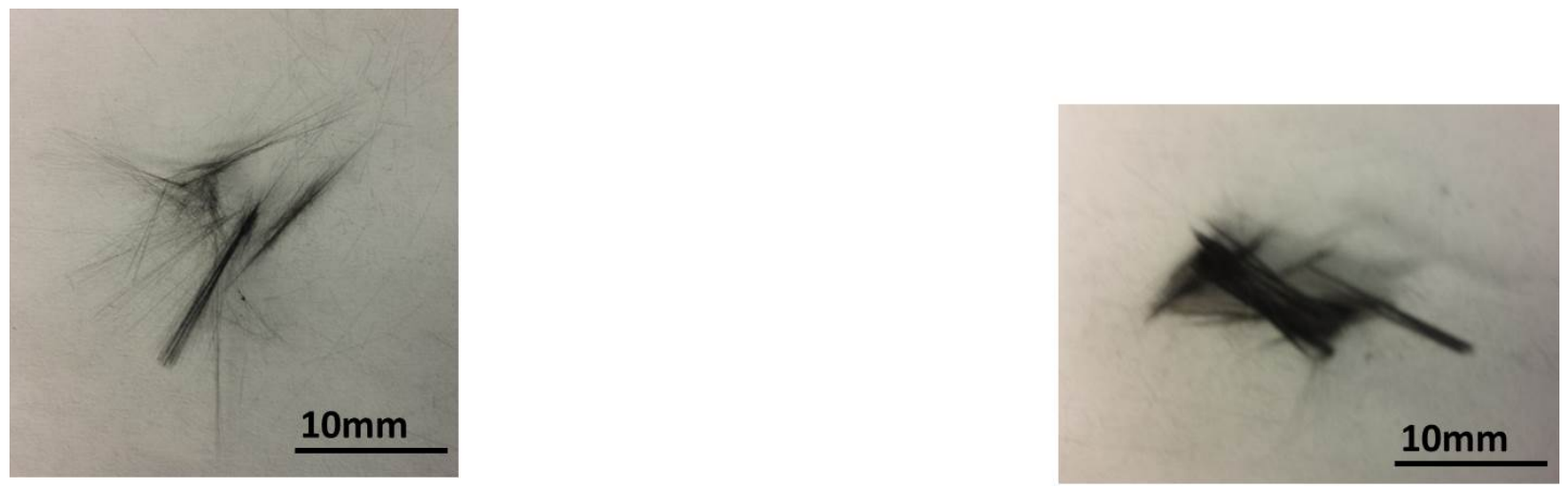

Figure 9. Fibers recovered from down selected fibers with epoxy plugs for length analysis (slow-fill 30wt\% LCF/PP edge-gated injection molding).

Table 2 provides a summary of mass loss of the sample coupons taken at Locations A, B and C from the slow-fill 30wt\% LCF/PP edge-gated plaque. Figures 10 to 12 illustrate the details of the fiber recovery procedure applied to separate carbon fibers from the PP resin for fiber length analyses for these locations. 


\begin{tabular}{|c|c|c|c|c|}
\hline Sample coupon & $\begin{array}{c}\text { Coupon } \\
\text { weight (g) }\end{array}$ & $\begin{array}{c}\text { After calcination } \\
\left(500^{\circ} \mathrm{C} \text { for } 2 \mathrm{~h}\right)\end{array}$ & $\begin{array}{l}\text { Carbon fiber } \\
\text { content (\%) }\end{array}$ & $\begin{array}{c}\text { Carbon fines } \\
\text { content (\%) }\end{array}$ \\
\hline Location A & 1.6023 & 0.4605 & 28.74 & 2.87 \\
\hline Location B & 1.5815 & 0.4481 & 28.33 & 2.05 \\
\hline Location C & 1.6244 & 0.4938 & 30.40 & 1.62 \\
\hline
\end{tabular}

Table 2. Summary of mass loss of coupons taken at Locations A, B and C from the slow-fill 30wt\% $\mathrm{LCF} / \mathrm{PP}$ edge-gated plaque.
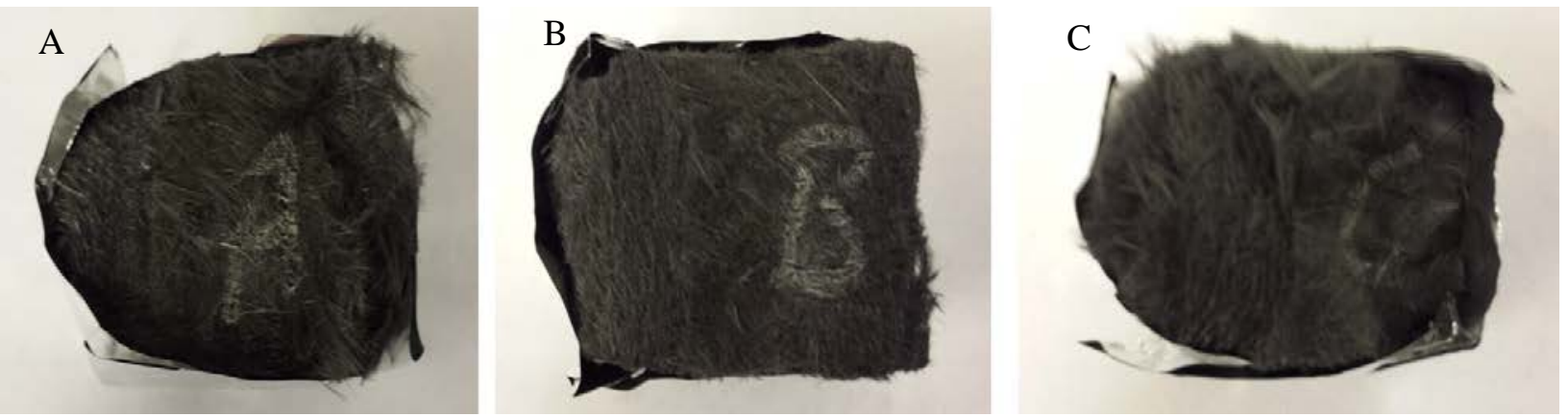

Figure 10. Fiber mats from Locations $A, B$, and $C$ from the slow-fill 30wt $\%$ LCF/PP edge-gated plaque recovered in argon at $500^{\circ} \mathrm{C}$ for 2 hours.
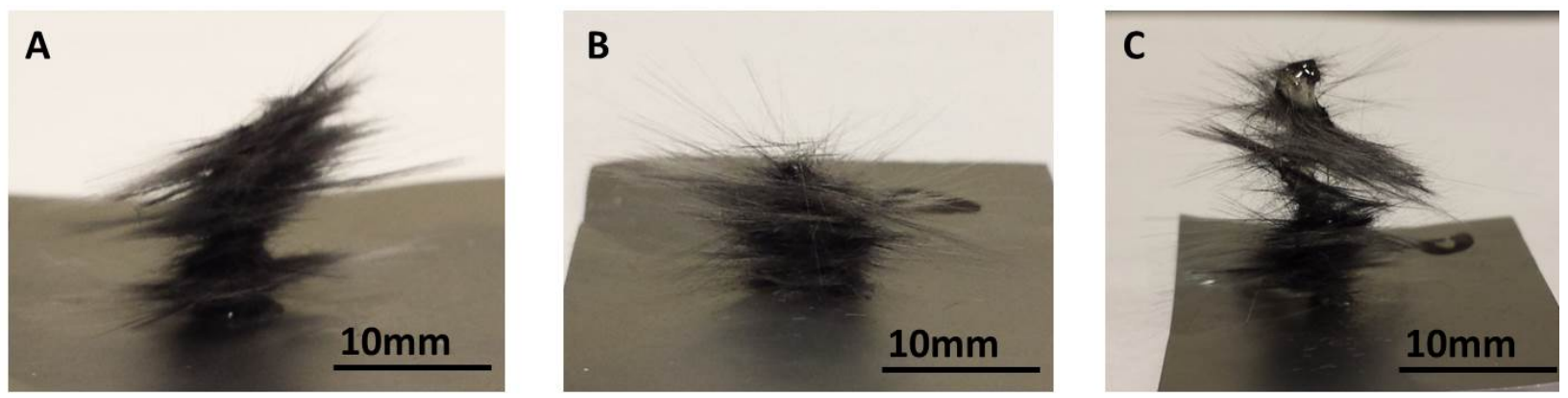

Figure 11. Down selected fibers with epoxy plugs from Locations A, B, and C from the slow-fill 30wt\% LCF/PP edge-gated plaque.
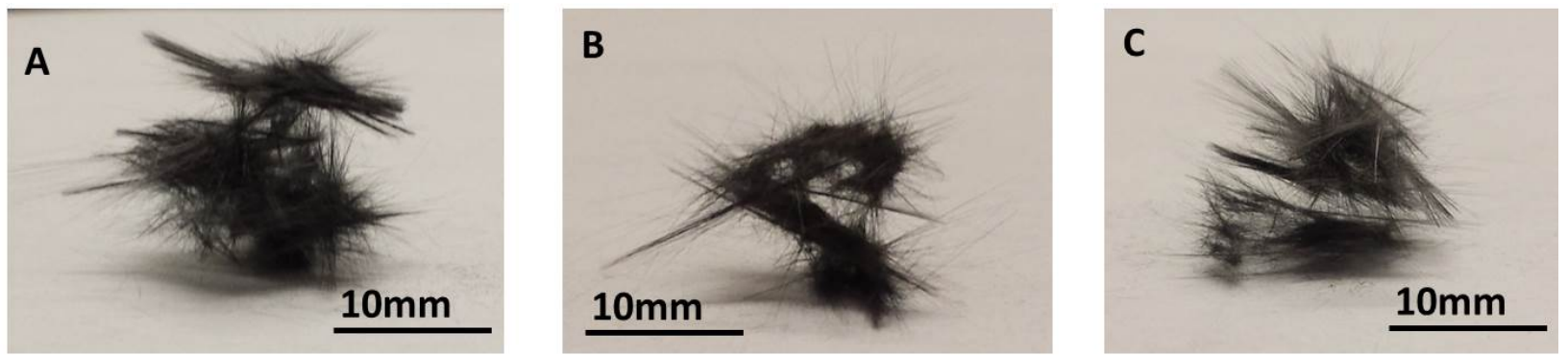

Figure 12. Carbon fibers at Locations A, B, and C recovered from down selected fibers with epoxy plugs for these locations illustrated in Figure 11. 
PNNL-24031

\subsection{A Method to Correct Bias in Fiber Orientation Data Caused by Misalignment of Axes (PNNL)}

The misalignment between the flow direction and the measurement surface (illustrated and discussed in Section 4.1) creates some bias in the fiber orientation data measured on a center-gated plaque although this misalignment diminishes when moving away from the gate to the downstream locations. Therefore, the as-measured data, particularly for Location A need to be corrected so that fiber orientation data are reported in the truly flow/cross-flow direction axes system. This section proposes a method to correct the fiber orientation data for the center-gated plaque.

The measurement surface of the sample taken at Location A on the center-gated plaque forms an angle about 25.5 degrees with the radial flow direction (Figure 3). Intuitively, it is necessary to rotate the measured orientation tensor for this surface a 25.5-degree angle to express it in the flow/cross-flow direction axes system. To do so, it is necessary to have all the measured values of the orientation tensor components, $A_{i j}$. However, as discussed in Section 4.1, the current fiber orientation measurement method does not provide the actual values of $A_{12}$ and $A_{23}$ but provides only their lower bounds and upper bounds. The actual values of $A_{12}$ and $A_{23}$ are not known but are expected to be comprised between the corresponding lower and upper bounds. Therefore, an adequate approximation is needed to estimate the values of $A_{12}$ and $A_{23}$. We propose to use the ASMI mid-plane solution for $A_{12}$ and $A_{23}$ expressed in the 1-2-3 coordinate system (Figure 3 ) in the measured fiber orientation tensor and then express this tensor in the truly flow/cross-flow direction axes system. This method allows the correction of the orientation data for Location A with the condition that the ASMI mid-plane solution reasonably agrees with the measured data for the other locations so that the ASMI solution for $A_{12}$ and $A_{23}$ computed at the measurement surface of Location A can be used in the fiber orientation tensor rotation to the flow-/cross-flow direction coordinate system.

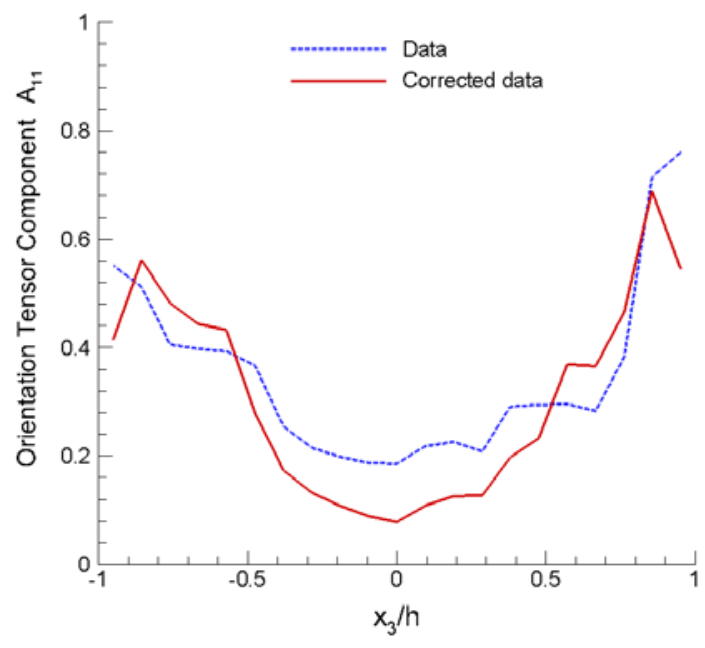

(a)

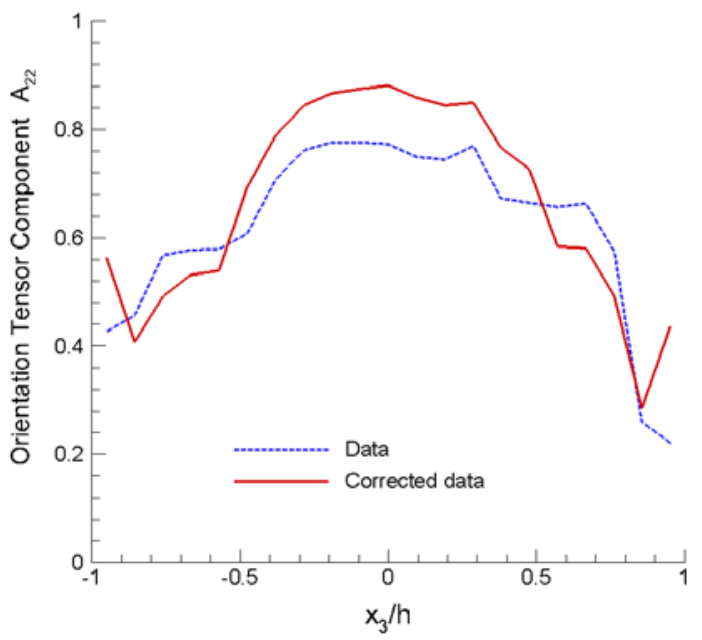

(b)

Figure 13: (a) As-received and corrected data for $A_{11}$, and (b) As-received and corrected data for $A_{22}$ of Location A on the slow-fill 50wt\% LCF/PP center-gated plaque.

Figures 13(a) and 13(b) show the as-received data and data corrected using the present method for components $A_{11}$ and $A_{22}$ at Location A of the slow-fill 50wt\% LCF/PP center-gated plaque. We observe significant differences between as-received data curves and the corrected data curves. These differences are caused by the misalignment between the flow direction and the measurement surface that is 
significant at Location A of the center-gated plaque. However, as the misalignment becomes smaller at the locations away from the gate, the differences between the as-received data and corrected data become much less significant and within the experimental scatter as this is observed for Locations B and C. Figures 14(a) and 14(b) show the as-received data and data corrected using this correction method for components $A_{11}$ and $A_{22}$ at Location $\mathrm{B}$ of the same plaque. For this location, the as-received data curves are quite close to the corrected data plots.

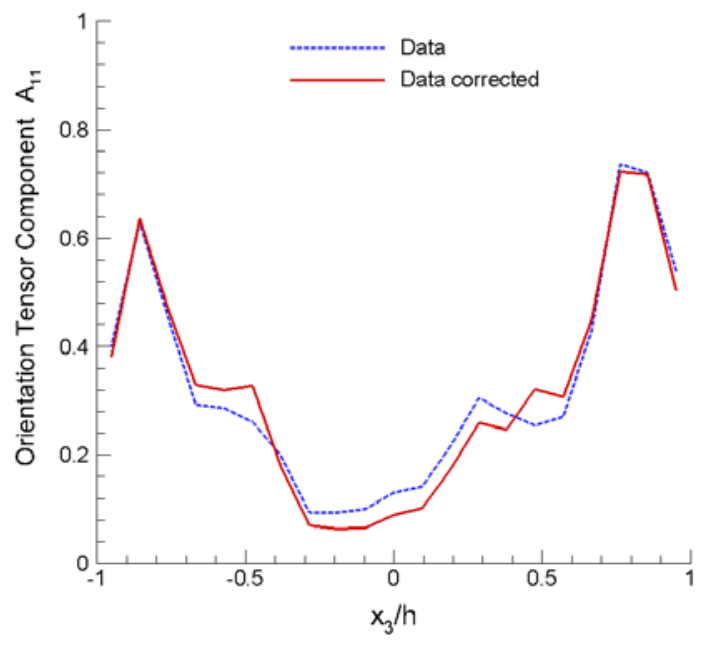

(a)

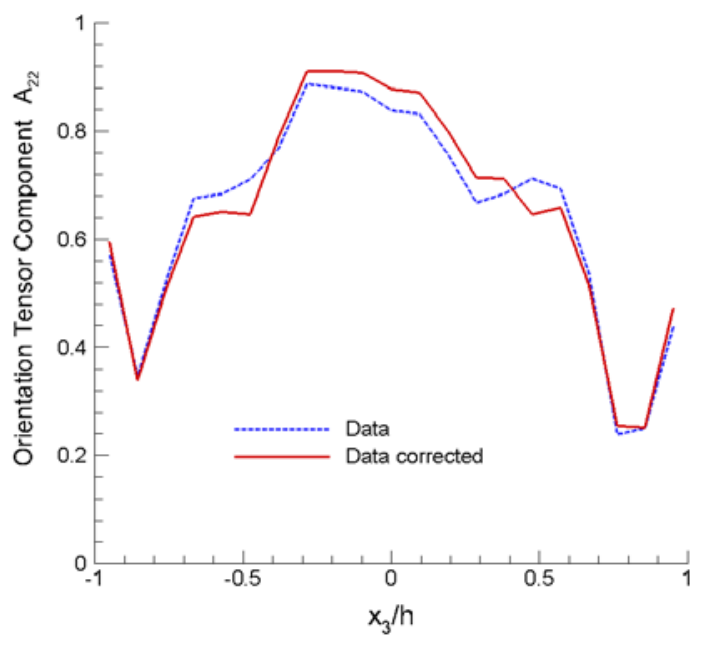

(b)

Figure 14: (a) As-received and corrected data for $A_{11}$, and (b) As-received and corrected data for $A_{22}$ of Location B on the slow-fill 50wt\% LCF/PP center-gated plaque.

\subsection{Process Modeling of PlastiComp Plaques Using ASMI (PNNL)}

PNNL received three new sets of fiber orientation data from Purdue for the samples at Locations A, B and $\mathrm{C}$ (Figure 1) of the PlastiComp plaques listed in Section 4.1. These samples were cut from fast-fill 30wt\% LCF/PP center-gated, fast-fill 50wt\% LCF/PA66 edge-gated and fast-fill 50wt\% LCF/PA66 center-gated plaques. The data for the fast-fill 50wt\% LCF/PA66 edge-gated plaque were discarded because they exhibited unusual variations due to measurement issues and could not be used for model validation. Fiber orientation re-measurements for this plaque were discussed with Purdue and the new data will be reported later. On discussion with Autodesk, PNNL used the fiber orientation data for the fast-fill 30wt\% LCF/PP and 50wt\% LCF/PA66 center-gated plaques to conduct the validation of ASMI mid-plane fiber orientation predictions using the anisotropic rotary diffusion reduced strain closure (ARD-RSC) model [5]. In addition, in light of the data correction for Location A of center-gated plaques discussed in Section 4.2, predicted fiber orientations for the slow-fill 50wt\% LCF/PP center-gated plaque previously analyzed are also compared to the corrected data for this plaque.

Figures 15(a) and 15(b) compare the as-received fiber orientation data and data corrected using the axis misalignment correction method with the ASMI mid-plane results for components $A_{11}$ and $A_{22}$ at Location A of the slow-fill 50wt\% LCF/PP center-gated plaque. These figures show that ASMI solutions agree well with the corrected data. Figures 16(a) and 16(b) show the comparisons of results for Location $\mathrm{B}$ on the same plaque. For this location which is sufficiently away from the gate, ASMI predictions agree with both the as-received and corrected data. Tables 3 to 6 report the tensile and flexural moduli calculated based on predicted fiber orientations, as-received fiber orientation and corrected fiber 
orientation data for Locations $\mathrm{A}$ and $\mathrm{B}$ on this plaque. The results for Location A show that the moduli based on predicted fiber orientation globally in closer agreement with the modulus values based on the corrected orientation data whereas the modulus results based on predicted orientation for Location B on the same plaque agree well with the values using as-received or corrected orientation data. These findings confirm that only the correction for the fiber orientation data for Location A of any PlastiComp centergated plaque is needed.

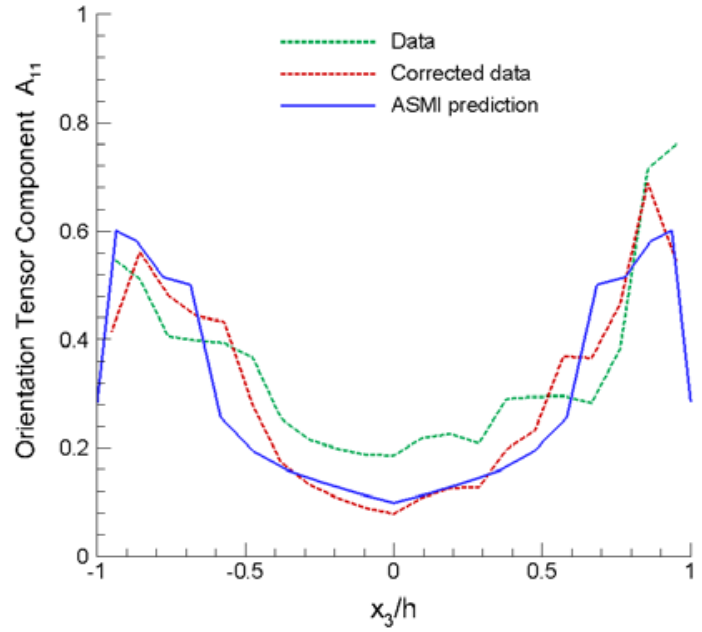

(a)

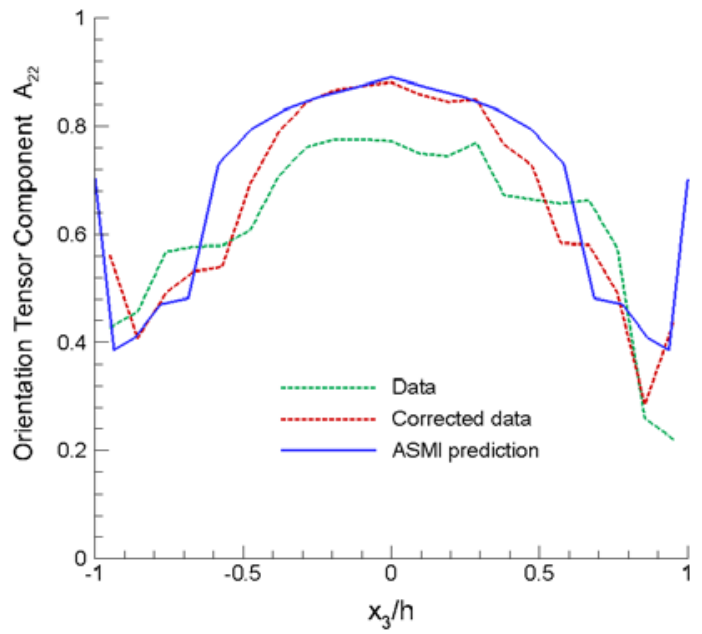

(b)

Figure 15: Predictions, as-received data and corrected data for the fiber orientation tensor components in the flow- and cross-flow directions: (a) $A_{11}$, and (b) $A_{22}$ for Location A on the slow-fill 50wt\% LCF/PP center-gated plaque.

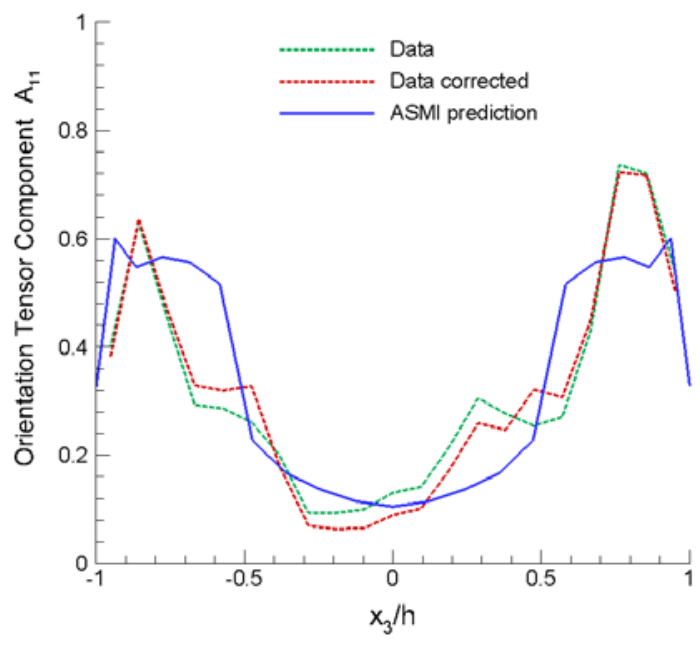

(a)

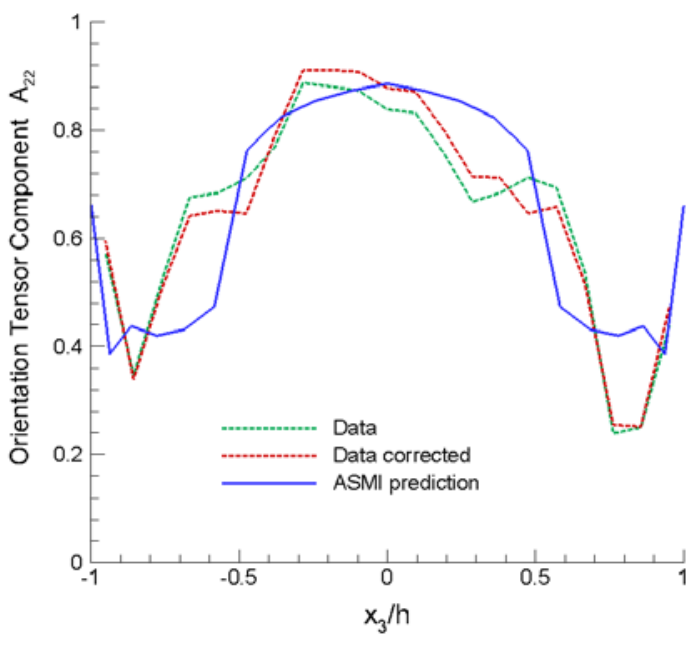

(b)

Figure 16: Predictions, as-received data and corrected data for the fiber orientation tensor components in the flow- and cross-flow directions: (a) $A_{11}$, and (b) $A_{22}$ for Location B on the slow-fill 50wt\% LCF/PP center-gated plaque. 


\begin{tabular}{|c|c|c|c|}
$\begin{array}{c}\text { Tensile } \\
\text { Modulus }\end{array}$ & $\begin{array}{c}\boldsymbol{E}_{\mathbf{1 1}} \text { (as-received } \\
\text { orientation data) MPa }\end{array}$ & $\begin{array}{c}\boldsymbol{E}_{\mathbf{1 1}} \text { (corrected } \\
\text { orientation data) MPa }\end{array}$ & $\begin{array}{c}\boldsymbol{E}_{\mathbf{1 1}} \text { (predicted orientation) } \\
\text { MPa }\end{array}$ \\
\hline Loc. A & $21174(2.55 \%)$ & $19071 \quad(8.2 \%)$ & 20634 \\
\hline Loc. B & $20322(13.49 \%)$ & $20219(14.07 \%)$ & 23064 \\
\hline
\end{tabular}

Table 3. Computed $E_{11}$ based on as-received, corrected fiber orientation data, and predicted fiber orientation at Locations A and B in the slow-fill 50wt\% LCF/PP center-gated plaque.

\begin{tabular}{|c|c|c|c|c|}
\hline $\begin{array}{c}\text { Tensile } \\
\text { Modulus }\end{array}$ & $\begin{array}{c}\boldsymbol{E}_{22} \text { (as-received } \\
\text { orientation data) MPa }\end{array}$ & $\begin{array}{c}\boldsymbol{E}_{22} \text { (corrected } \\
\text { orientation data) MPa }\end{array}$ & $\begin{array}{c}\boldsymbol{E}_{22} \text { (predicted orientation) } \\
\text { MPa }\end{array}$ \\
\hline Loc. $\mathbf{A}$ & $41332(11.79 \%)$ & $45905 \quad(0.66 \%)$ & 46206 \\
\hline Loc. B & $44762(3.60 \%)$ & $45437(5.03 \%)$ & 43152 \\
\hline
\end{tabular}

Table 4. Computed $E_{22}$ based on as-received, corrected fiber orientation data, and predicted fiber orientation at Locations A and B in the slow-fill 50wt\% LCF/PP center-gated plaque.

\begin{tabular}{|c|c|c|c|}
\hline $\begin{array}{l}\text { Flexural } \\
\text { Modulus }\end{array}$ & $\begin{array}{c}\boldsymbol{D}_{\mathbf{1 1}} \text { (as-received } \\
\text { orientation data) } \\
\text { MPa.mm }\end{array}$ & $\begin{array}{c}\boldsymbol{D}_{\mathbf{1 1}} \text { (corrected } \\
\text { orientation data) } \\
\text { MPa.mm }\end{array}$ & $\begin{array}{c}\boldsymbol{D}_{\mathbf{1 1}} \text { (predicted } \\
\text { orientation) } \\
\text { MPa.mm }\end{array}$ \\
\hline Loc. A & $95315(9.19 \%)$ & $88242 \quad(1.92 \%)$ & 86552 \\
\hline Loc. B & $92847(0.36 \%)$ & $92986(0.2 \%)$ & 93179 \\
\hline
\end{tabular}

Table 5. Computed $D_{11}$ based on as-received, corrected fiber orientation data, and predicted fiber orientation at Locations A and B in the slow-fill 50wt\% LCF/PP center-gated plaque.

\begin{tabular}{|c|c|c|c|}
\hline $\begin{array}{l}\text { Flexural } \\
\text { Modulus }\end{array}$ & $\begin{array}{c}\boldsymbol{D}_{22} \text { (as-received } \\
\text { orientation data) } \\
\text { MPa.mm }\end{array}$ & $\begin{array}{c}\boldsymbol{D}_{22} \text { (corrected } \\
\text { orientation data) } \\
\text { MPa.mm }\end{array}$ & $\begin{array}{c}\boldsymbol{D}_{22} \text { (predicted } \\
\text { orientation) } \\
\text { MPa.mm }\end{array}$ \\
\hline Loc. A & $97092 \quad(13.44 \%)$ & 102389 (7.57\%) & 110144 \\
\hline Loc. B & 100929 (0.86\%) & 100143 (1.64\%) & 101783 \\
\hline
\end{tabular}

Table 6. Computed $D_{22}$ based on as-received, corrected fiber orientation data, and predicted fiber orientation at Locations A and B in the slow-fill 50wt\% LCF/PP center-gated plaque. 
PNNL also conducted ASMI mid-plane analyses of the fast-fill 30wt\% LCF/PP center-gated and fastfill 50wt\% LCF/PA66 center-gated plaques upon receiving the fiber orientation data from Purdue. The axis misalignment correction method presented in Section 4.4 was applied to correct the orientation data for Locations A of these plaques. Figures 17 to 19 report the comparisons between the predicted and measured fiber orientation components in the flow and cross-flow directions ( $A_{11}$ and $A_{22}$ ) for Locations $\mathrm{A}, \mathrm{B}$ and $\mathrm{C}$ on the fast-fill 30wt\% LCF/PP center-gated plaque.

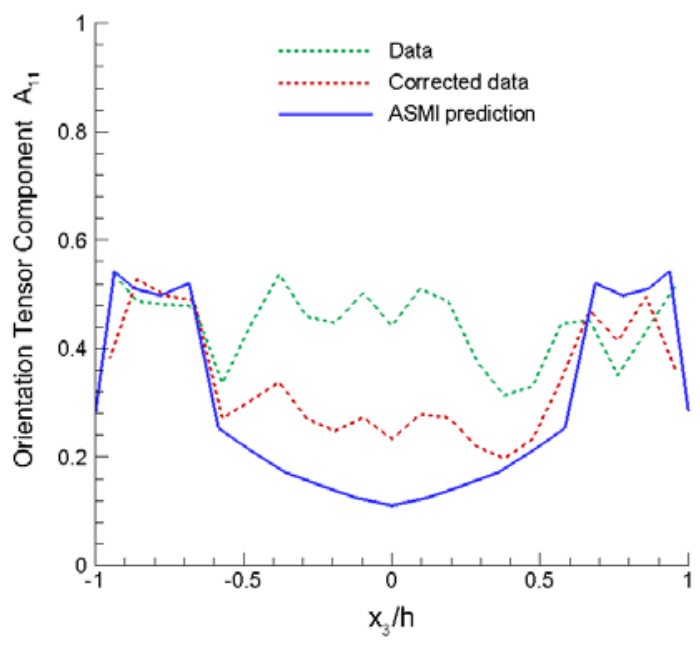

(a)

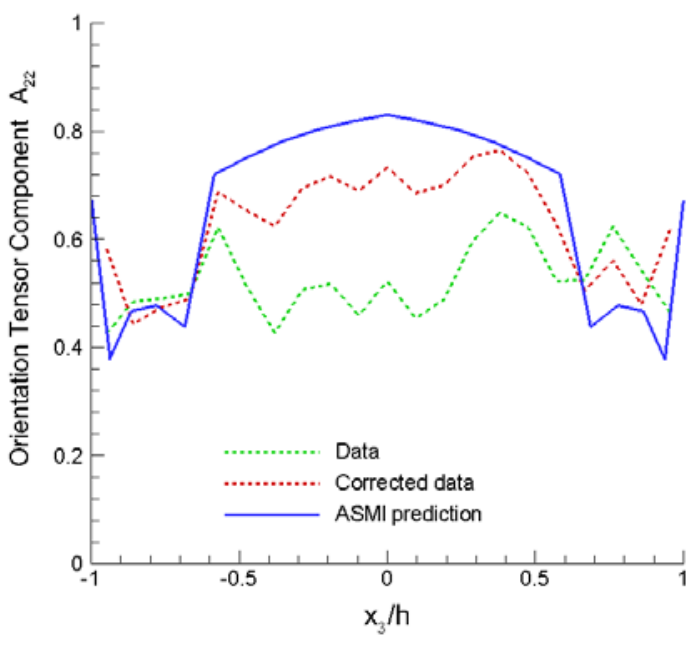

(b)

Figure 17: Predictions, as-received data and corrected data for the fiber orientation tensor components in the flow- and cross-flow directions: (a) $A_{11}$, and (b) $A_{22}$ for Location A on the fast-fill 30wt\% LCF/PP center-gated plaque.

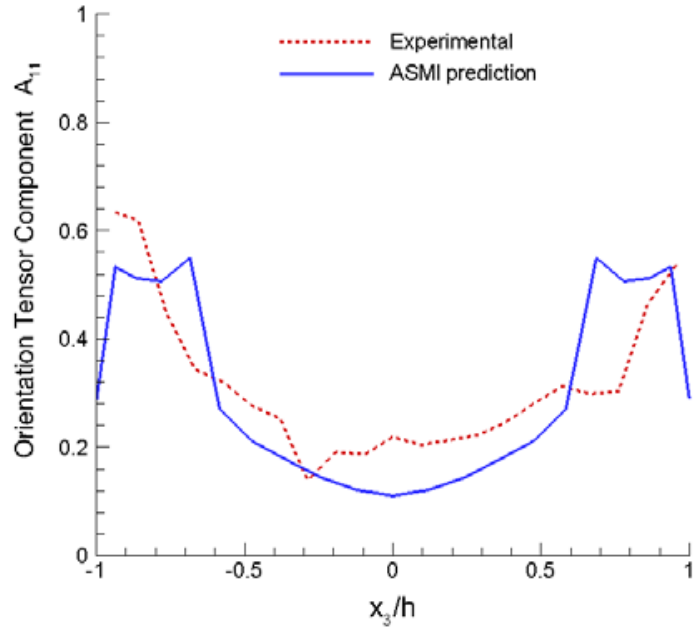

(a)

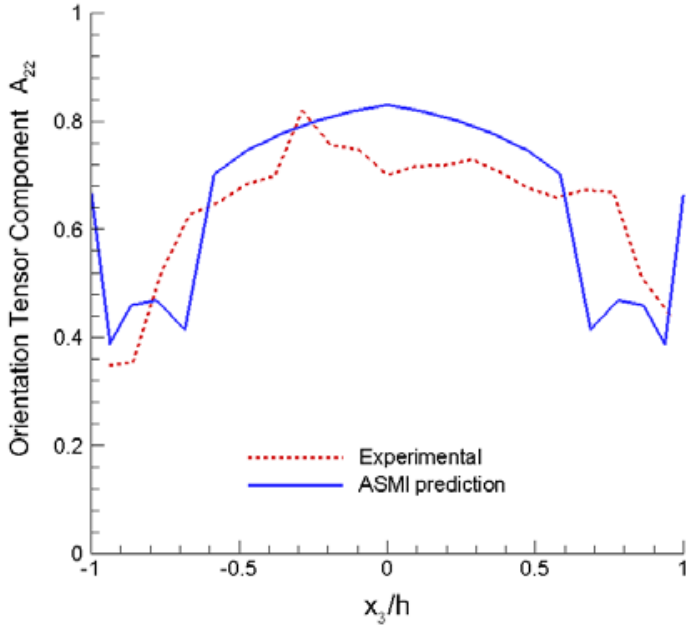

(b)

Figure 18: Predictions and measured data for the fiber orientation tensor components in the flow- and cross-flow directions: (a) $A_{11}$, and (b) $A_{22}$ for Location B on the fast-fill 30wt\% LCF/PP center-gated plaque. 


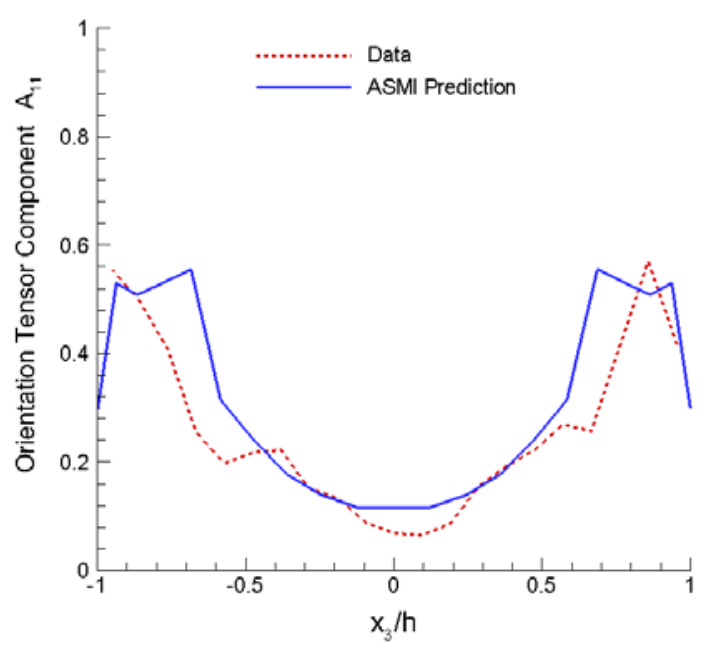

(a)

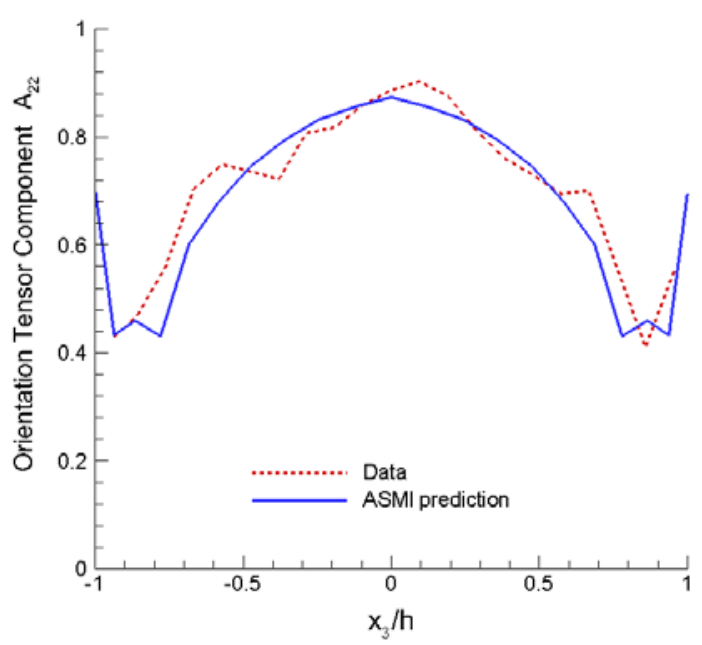

(b)

Figure 19: Predictions and measured data for the fiber orientation tensor components in the flow- and cross-flow directions: (a) $A_{11}$, and (b) $A_{22}$ for Location C on the fast-fill 30wt\% LCF/PP center-gated plaque.

Tables 7 to 10 report the tensile and flexural moduli calculated based on the predicted and measured fiber orientations for Locations A, B and C on this plaque. There is a globally good agreement of results except for the predicted tensile modulus $E_{11}$ for Location $C$ that does not meet the $15 \%$ accuracy criterion.

\begin{tabular}{|c|c|c|}
\hline Tensile Modulus & $\begin{array}{c}\boldsymbol{E}_{\mathbf{1 1}} \text { (measured } \\
\text { orientation) } \mathrm{MPa}\end{array}$ & $\begin{array}{c}\boldsymbol{E}_{\mathbf{1 1}} \text { (predicted } \\
\text { orientation) } \mathrm{MPa}\end{array}$ \\
\hline $\begin{array}{c}\text { Loc. } \mathbf{A} \\
\text { (using corrected data) }\end{array}$ & 10819 (1.44\%) & 10975 \\
\hline Loc. B & 10819 (2.40\%) & 11079 \\
\hline Loc. C & 9189 (23.21\%) & 11322 \\
\hline
\end{tabular}

Table 7. Computed $E_{11}$ based on measured and predicted fiber orientations at Locations $\mathrm{A}, \mathrm{B}$ and $\mathrm{C}$ in the fast-fill 30wt\% LCF/PP center-gated plaque. 
PNNL-24031

\begin{tabular}{|c|c|c|}
\hline Tensile Modulus & $\begin{array}{c}\boldsymbol{E}_{22} \text { (measured } \\
\text { orientation) } \mathrm{MPa}\end{array}$ & $\begin{array}{c}\boldsymbol{E}_{22} \text { (predicted } \\
\text { orientation) } \mathrm{MPa}\end{array}$ \\
\hline $\begin{array}{c}\text { Loc. } \mathbf{A} \\
\text { (using corrected data) }\end{array}$ & 21278 (12.96\%) & 24036 \\
\hline Loc. B & 23390 (1.52\%) & 23746 \\
\hline Loc. C & $26760 \quad(14.05 \%)$ & 23000 \\
\hline
\end{tabular}

Table 8. Computed $E_{22}$ based on measured and predicted fiber orientations at Locations $\mathrm{A}, \mathrm{B}$ and $\mathrm{C}$ in the fast-fill 30wt\% LCF/PP center-gated plaque.

\begin{tabular}{|c|c|c|}
\hline Flexural Modulus & $\begin{array}{c}\boldsymbol{D}_{\mathbf{1 1}} \text { (measured } \\
\text { orientation) MPa.mm }\end{array}$ & $\begin{array}{c}\boldsymbol{D}_{\mathbf{1 1}} \text { (predicted } \\
\text { orientation) MPa.mm }\end{array}$ \\
\hline $\begin{array}{c}\text { Loc. A } \\
\text { (using corrected data) }\end{array}$ & $45789(3.47 \%)$ & 47378 \\
\hline Loc. B & 49961 & $(4.28 \%)$ \\
\hline Loc. $\mathbf{C}$ & $44885(8.42 \%)$ & 47824 \\
\hline
\end{tabular}

Table 9. Computed $D_{11}$ based on measured and predicted fiber orientations at Locations A, B and C in the fast-fill 30wt\% LCF/PP center-gated plaque.

\begin{tabular}{|c|c|c|}
\hline Flexural Modulus & $\begin{array}{c}\boldsymbol{D}_{\mathbf{2 2}} \text { (measured } \\
\text { orientation) MPa.mm }\end{array}$ & $\begin{array}{c}\boldsymbol{D}_{\mathbf{2 2}} \text { (predicted } \\
\text { orientation) MPa.mm }\end{array}$ \\
\hline $\begin{array}{c}\text { Loc. A } \\
\text { (using corrected data) }\end{array}$ & 64284 (2.91\%) & 62413 \\
\hline Loc. B & 62168 (0.86\%) & 61633 \\
\hline Loc. C & $66960 \quad(10.73 \%)$ & 59773 \\
\hline
\end{tabular}

Table 10. Computed $D_{22}$ based on measured and predicted fiber orientations at Locations A, B and C in the fast-fill 30wt\% LCF/PP center-gated plaque.

Figures 20 to 22 report the comparisons between the predicted and measured fiber orientation components in the flow and cross-flow directions $\left(A_{11}\right.$ and $\left.A_{22}\right)$ for Locations $\mathrm{A}, \mathrm{B}$ and $\mathrm{C}$ on the fast-fill 50wt\% LCF/PA66 center-gated plaque. Tables 11 to 14 provide the tensile and flexural moduli calculated 
based on the predicted and measured fiber orientations for Locations $\mathrm{A}, \mathrm{B}$ and $\mathrm{C}$ on this plaque. There is a global agreement of results for Locations A and B while the predicted tensile moduli for Location C do not meet the $15 \%$ accuracy criterion. It is expected that refine data for data for Location A of this plaque and the re-measured data for the edge-gated plaque molded from 50wt\% LCF/PA66 under the same conditions would help assess the model parameters for this material in order to improve the agreement between the predicted and measured data.

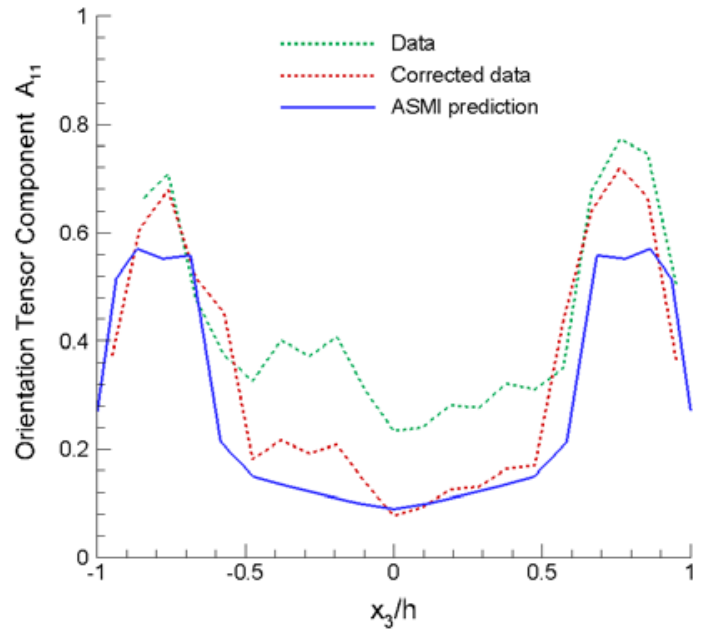

(a)

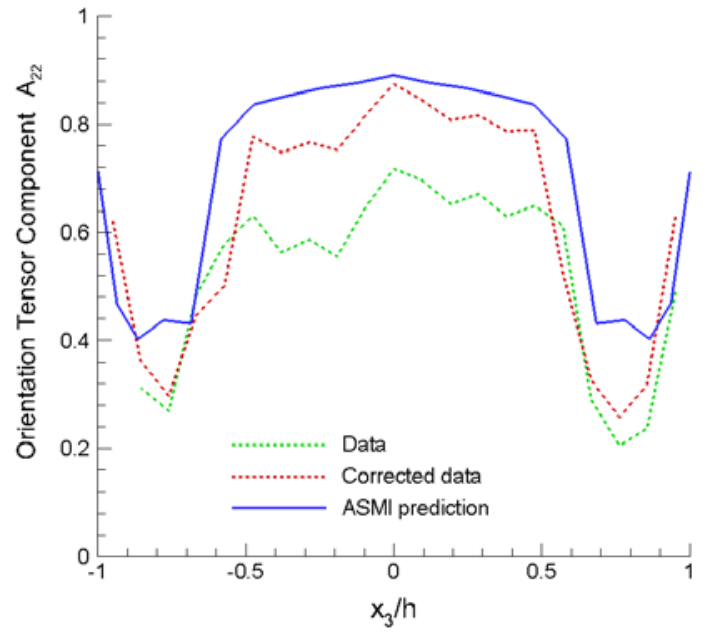

(b)

Figure 20: Predictions, as-received data and corrected data for the fiber orientation tensor components in the flow- and cross-flow directions: (a) $A_{11}$, and (b) $A_{22}$ for Location A on the fast-fill 50wt\% LCF/PA66 center-gated plaque.

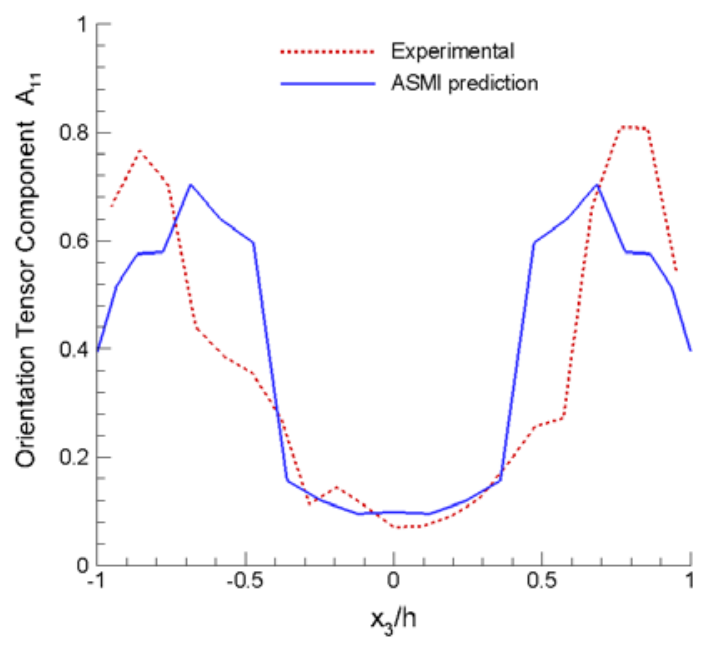

(a)

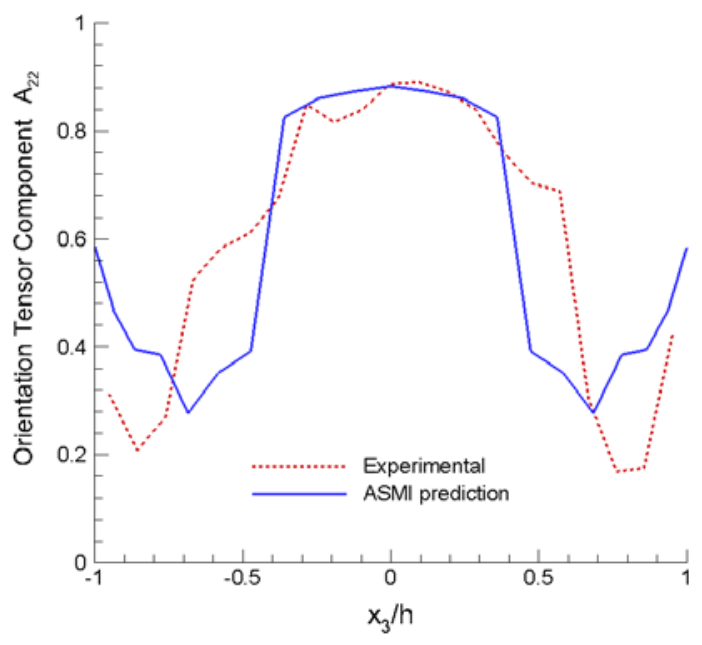

(b)

Figure 21: Predictions, as-received data and corrected data for the fiber orientation tensor components in the flow- and cross-flow directions: (a) $A_{11}$, and (b) $A_{22}$ for Location B on the fast-fill 50wt\% LCF/PA66 center-gated plaque. 


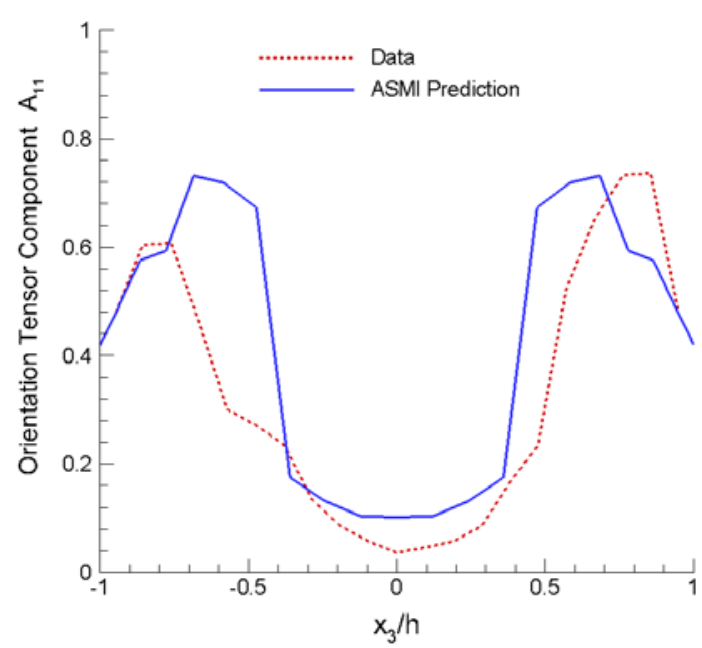

(a)

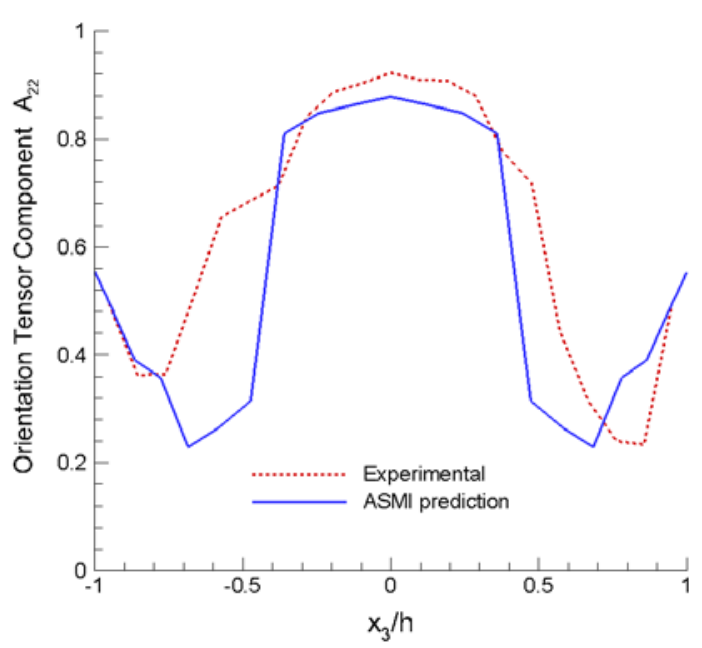

(b)

Figure 22: Predictions, as-received data and corrected data for the fiber orientation tensor components in the flow- and cross-flow directions: (a) $A_{11}$, and (b) $A_{22}$ for Location C on the fast-fill 50wt\% LCF/PA66 center-gated plaque.

\begin{tabular}{|c|c|c|}
\hline Tensile Modulus & $\begin{array}{c}\boldsymbol{E}_{\mathbf{1 1}} \text { (measured } \\
\text { orientation) } \mathrm{MPa}\end{array}$ & $\begin{array}{c}\boldsymbol{E}_{11} \text { (predicted } \\
\text { orientation) MPa }\end{array}$ \\
\hline $\begin{array}{c}\text { Loc. } \mathbf{A} \\
\text { (using corrected data) }\end{array}$ & 26902 (6.13\%) & 25254 \\
\hline Loc. B & 31744 (8.80\%) & 34536 \\
\hline Loc. C & 27944 (31.56\%) & 36763 \\
\hline
\end{tabular}

Table 11. Computed $E_{11}$ based on measured and predicted fiber orientations at Locations A, B and C in the fast-fill 50wt\% LCF/PA66 center-gated plaque.

\begin{tabular}{|c|c|c|}
\hline Tensile Modulus & $\begin{array}{c}\boldsymbol{E}_{22} \text { (measured } \\
\text { orientation) } \mathrm{MPa}\end{array}$ & $\begin{array}{c}\boldsymbol{E}_{22} \text { (predicted } \\
\text { orientation) MPa }\end{array}$ \\
\hline $\begin{array}{c}\text { Loc. } \mathbf{A} \\
\text { (using corrected data) }\end{array}$ & 51524 (13.89\%) & 58680 \\
\hline Loc. B & 51140 (8.25\%) & 46923 \\
\hline Loc. C & $54726 \quad(18.38 \%)$ & 44669 \\
\hline
\end{tabular}

Table 12. Computed $E_{22}$ based on measured and predicted fiber orientations at Locations $\mathrm{A}, \mathrm{B}$ and $\mathrm{C}$ in the fast-fill 50wt\% LCF/PA66 center-gated plaque. 
PNNL-24031

\begin{tabular}{|c|c|c|}
\hline Flexural Modulus & $\begin{array}{c}\boldsymbol{D}_{\mathbf{1 1}} \text { (measured } \\
\text { orientation) MPa.mm }\end{array}$ & $\begin{array}{c}\boldsymbol{D}_{11} \text { (predicted } \\
\text { orientation) MPa.mm }\end{array}$ \\
\hline $\begin{array}{c}\text { Loc. } \mathbf{A} \\
\text { (using corrected data) }\end{array}$ & 116845 (12.97\%) & 101693 \\
\hline Loc. B & 145934 (14.61\%) & 124614 \\
\hline Loc. C & 125332 (2.65\%) & 128654 \\
\hline
\end{tabular}

Table 13. Computed $D_{11}$ based on measured and predicted fiber orientations at Locations $\mathrm{A}, \mathrm{B}$ and C in the fast-fill 50wt\% LCF/PA66 center-gated plaque.

\begin{tabular}{|c|c|c|}
\hline Flexural Modulus & $\begin{array}{c}\boldsymbol{D}_{\mathbf{2 2}} \text { (measured } \\
\text { orientation) MPa.mm }\end{array}$ & $\begin{array}{c}\boldsymbol{D}_{\mathbf{2 2}} \text { (predicted } \\
\text { orientation) MPa.mm }\end{array}$ \\
\hline $\begin{array}{c}\text { Loc. } \mathbf{A} \\
\text { (using corrected data) }\end{array}$ & 118048 (17.66\%) & 138890 \\
\hline Loc. B & 95853 (15.28\%) & 110495 \\
\hline Loc. $\mathrm{C}$ & 110257 (5.07\%) & 104667 \\
\hline
\end{tabular}

Table 14. Computed $D_{22}$ based on measured and predicted fiber orientations at Locations $\mathrm{A}, \mathrm{B}$ and $\mathrm{C}$ in the fast-fill 50wt\% LCF/PA66 center-gated plaque.

PNNL received a new ASMI research version that contains the new features regarding improvements of 3D fiber orientation modeling and the option to use the reduced order model (ROM) for fiber length distribution (FLD). PNNL conducted the assessment of 3D fiber orientation predictions for PlastiComp plaques by comparing 3D modeling results with the mid-plane results and with the experimental data. PNNL also discussed the ASMI 3D models for PlastiComp plaques and the analysis results from these models with Autodesk. At this time, 3D ASMI modeling has not achieved the same level of accuracy as the ASMI mid-plane modeling does. PNNL continues the discussion with Autodesk on this work that will be presented in the next report. At the time of this report, the length data for PlastiComp plaques are not available to validate the FLD model for these plaques.

\subsection{Implementation and Improvements of Process Models in ASMI (Autodesk)}

Autodesk delivered a research version of AMI to PNNL. The research version included the improved 3D fiber orientation solver and implemented ROM/POD fiber length model in the mid-plane, dualdomain and 3D solvers. 
The new fiber orientation solver of ASMI 3D has been tested for several long-carbon-fiber plaques. Figure 23 illustrates the 3D mesh of the edge-gated plaque molded with PlastiComp 50wt\% LCF/PP using a fast injection rate. The measured fiber orientation data are compared with the predictions by the previous version of ASMI (ASMI 2015) and by the new research version in Figure 24. The new fiber solver yields much better fiber orientation prediction than the previous version as the prediction reasonably matches the data in the shell layer and captures the transverse orientation in the core, especially in locations B and C. The previous version gives a very small orientation component in the cross-flow direction through the thickness. However, the core width predicted by the new solver is still much narrower than observed in the experimental data. Autodesk will continue to work on improving the 3D orientation solver.

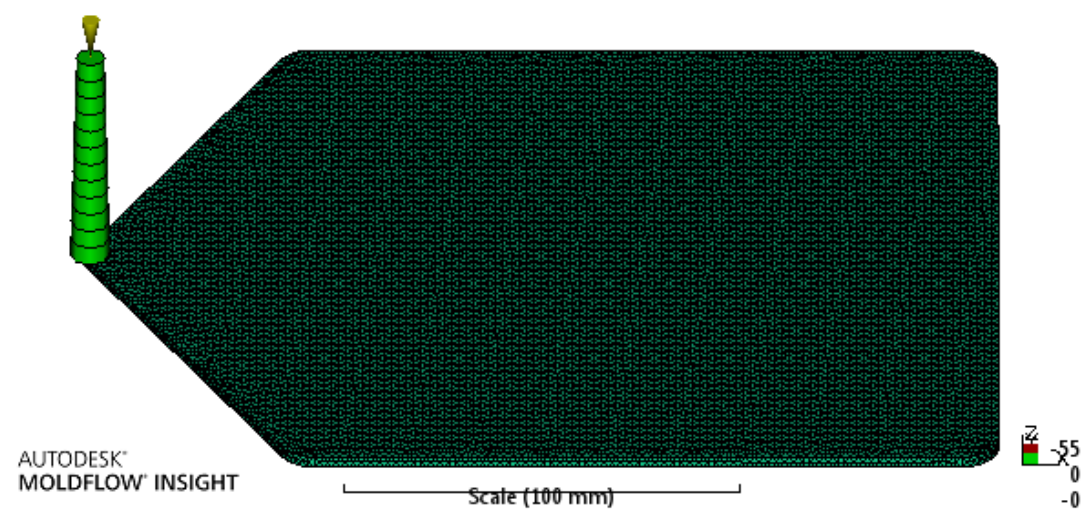

Figure 23: 3D mesh of the edge-gated plaque. 
PNNL-24031

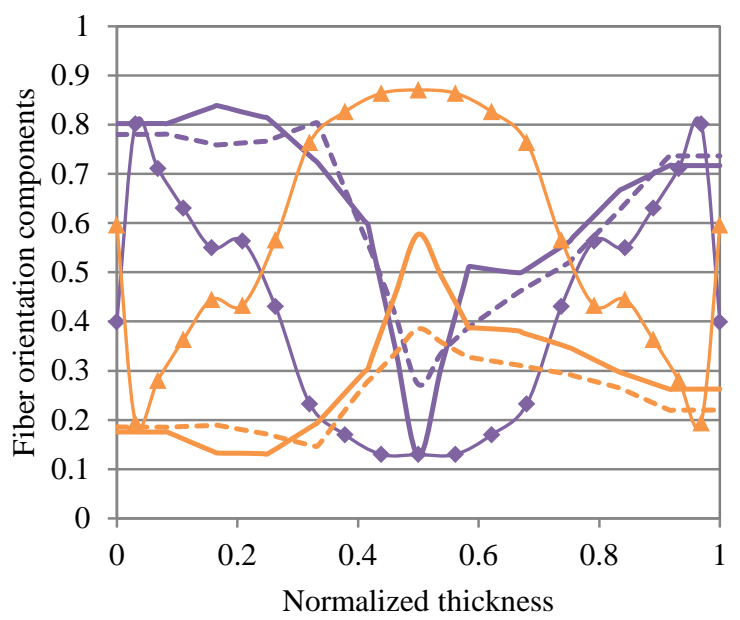

\section{Location A}

$\longrightarrow$ A11 (Data)

- - - A11 (Old, ARD-RSC)

— A11 (New, ARD-RSC)

$\longrightarrow$ A22 (Data)

$-\infty$ A22 (Old, ARD-RSC)

A22 (New, ARD-RSC)

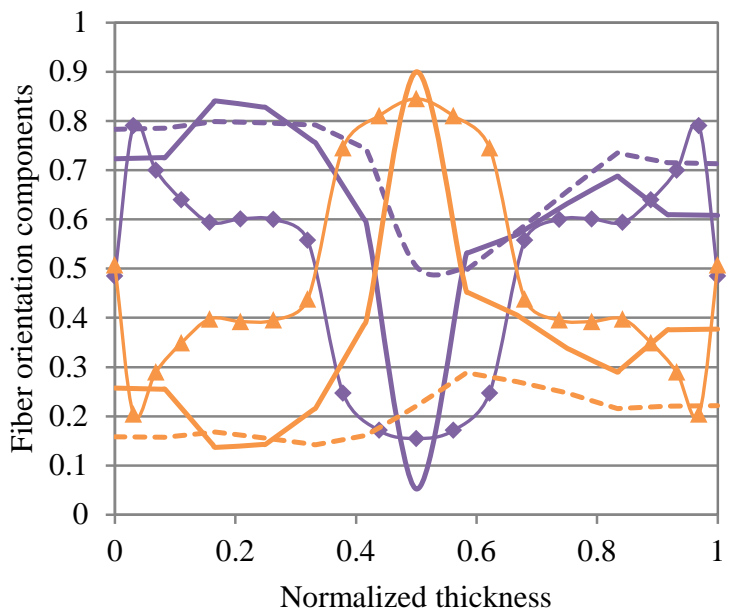

\section{Location B}

$\longrightarrow$ A11 (Data)

- - - A11 (Old, ARD-RSC)

A11 (New, ARD-RSC)

$\longrightarrow$ A22 (Data)

- - A22 (Old, ARD-RSC)

A22 (New, ARD-RSC)

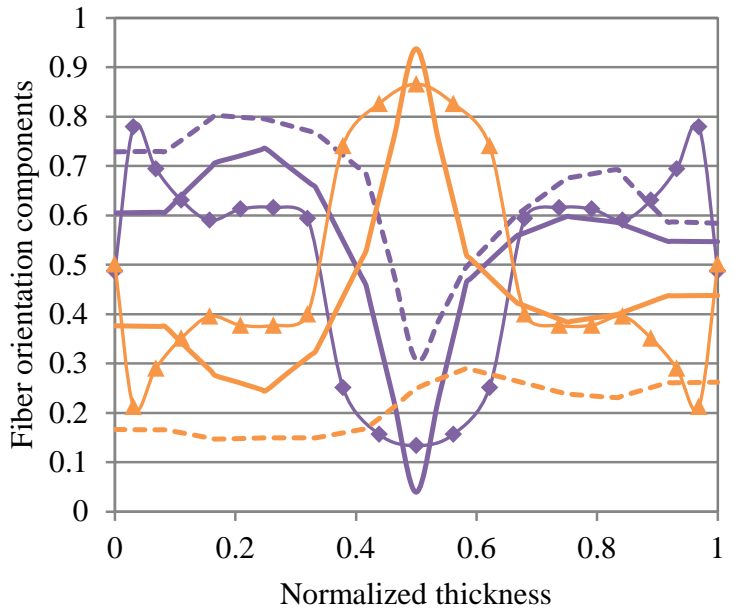

Location C

$\longrightarrow$ A11 (Data)

- - - A11 (Old, ARD-RSC)

A11 (New, ARD-RSC)

$\longrightarrow$ A22 (Data)

-

A22 (New, ARD-RSC)

Figure 24. Comparison of the ASMI orientation predictions using the old and new 3D solvers with the experimental data for the fast-filled 50wt\% LCF/PP edge-gated plaque (ARD-RSC, anisotropic rotary diffusion reduced strain closure). 
PNNL-24031

\section{Publications/Presentations}

[1] Wang J, BN Nguyen, R Mathur, B Sharma, MD Sangid, F Costaa, X Jin, CL Tucker, and LS Fifield, "Fiber Orientation in Injection Molded Long Carbon fiber Thermoplastic Composites." In Proceedings of the SPE ANTEC 2015 Conference, paper Nr. 2139172.

\section{Patents}

None

\section{$7 \quad$ Future Plans}

Purdue will refine fiber orientation measurements for Locations A of the fast-fill 30wt\% LCF/PP center-gated and fast-fill 50wt\% LCF/PA66 center-gated plaques. In addition, Purdue will re-measure fiber orientations at Locations A, B and C for the fast-fill 50wt\% LCF/PA66 edge-gated plaque. The refine and re-measured data will be provided to PNNL. With PNNL's assistance, Purdue will also complete fiber length measurements for the plaques and samples selected for the go/no-go list of validations. Fiber orientation and fiber length distribution data from locations A, B, and C in composite plaques representing variations in key material and molding parameters will be used to validate ASMI fiber orientation and fiber length predictions for these parameters toward making the go/no-go point. Agreement within 15\% between mechanical performance values in terms of the principal elastic tensile and flexural moduli calculated from the experimentally determined and computed fiber orientation and length data for the 2D plaques on the go/no-go list will enable transition of the project to focus on the 3D complex part. When the project passes the go/no-go decision point Magna will kick off the tooling for the complex 3D part and PlastiComp will produce carbon fiber-filled materials to be used for part molding. 


\section{Budgetary Information}

\begin{tabular}{|c|c|c|c|c|c|c|c|c|c|c|c|c|c|c|c|c|c|c|c|c|c|c|}
\hline \multirow{4}{*}{ Baseline Reporting Quarter } & \multicolumn{14}{|c|}{ Budget Period 1} & \multicolumn{8}{|c|}{$\begin{array}{l}\text { Budget Period } \mathbf{2} \\
\end{array}$} \\
\hline & \multirow{2}{*}{\multicolumn{2}{|c|}{\begin{tabular}{c|} 
FY13-Q1 \\
$9 / 11 / 2012-Q 12 / 31 / 2012$
\end{tabular}}} & \multirow{2}{*}{\multicolumn{2}{|c|}{\begin{tabular}{c|} 
FY13-Q2 \\
$1 / 12013-0 / 312013$
\end{tabular}}} & \multirow{2}{*}{\multicolumn{2}{|c|}{\begin{tabular}{|c|} 
FY14-Q1 \\
$10 / 1 / 2013-12 / 31 / 2013$
\end{tabular}}} & \multirow{2}{*}{\multicolumn{2}{|c|}{$\begin{array}{c}\text { FY14QQ2 } \\
1 / 1 / 2014-3 / 31 / 2014\end{array}$}} & \multirow{2}{*}{\multicolumn{2}{|c|}{\begin{tabular}{|c|} 
FY14-Q3 \\
$4 / 1 / 2014-6 / 30 / 2014$ \\
\end{tabular}}} & \multirow{2}{*}{\multicolumn{2}{|c|}{$\begin{array}{c}\text { FY14-Q4 } \\
7 / 1 / 2014-9 / 30 / 2014\end{array}$}} & \multirow{2}{*}{\multicolumn{2}{|c|}{\begin{tabular}{|c|} 
FY15-Q1 \\
$10 / 1 / 2014-12 / 31 / 2014$ \\
\end{tabular}}} & \multirow{2}{*}{\multicolumn{2}{|c|}{$\begin{array}{c}\text { FY15-Q2 } \\
1 / 1 / 2015-3 / 31 / 2015\end{array}$}} & \multirow{2}{*}{\multicolumn{2}{|c|}{\begin{tabular}{c|} 
FY15-Q3 \\
$4 / 1 / 2015-6 / 30 / 2015$ \\
\end{tabular}}} & \multirow{2}{*}{\multicolumn{2}{|c|}{\begin{tabular}{|c|} 
FY15-Q4 \\
$7 / 1 / 2015-9 / 30 / 2015$ \\
\end{tabular}}} & \multirow{2}{*}{\multicolumn{2}{|c|}{$\begin{array}{c}\text { FY16-Q1 } \\
10 / 1 / 2015-12 / 31 / 2015\end{array}$}} \\
\hline & & & & & & & & & & & & & & & & & & & & & & \\
\hline & Q1 & $\begin{array}{c}\text { Cumulative } \\
\text { Total }\end{array}$ & Q2 & \begin{tabular}{c|}
$\begin{array}{c}\text { Cumulative } \\
\text { Total }\end{array}$ \\
\end{tabular} & Q1 & $\begin{array}{c}\text { Cumulative } \\
\text { Total }\end{array}$ & Q2 & 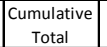 & Q3 & $\begin{array}{c}\text { Cumulative } \\
\text { Total }\end{array}$ & Q4 & \begin{tabular}{|c|}
$\begin{array}{c}\text { Cumulative } \\
\text { Total }\end{array}$ \\
\end{tabular} & Q1 & \begin{tabular}{|c|}
$\begin{array}{c}\text { Cumulative } \\
\text { Total }\end{array}$ \\
\end{tabular} & $\mathrm{Q}_{2}$ & \begin{tabular}{|c|}
$\begin{array}{c}\text { Cumulative } \\
\text { Total }\end{array}$ \\
\end{tabular} & Q3 & $\begin{array}{c}\text { Cumulative } \\
\text { Total }\end{array}$ & Q4 & $\begin{array}{c}\text { Cumulative } \\
\text { Total }\end{array}$ & Q1 & $\begin{array}{c}\text { Cumulative } \\
\text { Total }\end{array}$ \\
\hline \multicolumn{23}{|l|}{ Baseline Cost Plan } \\
\hline Federal Share & $\$ 6,808$ & $\$ 6,808$ & $\$ 2,536$ & $\$ 9,344$ & $\$ 62,859$ & $\$ 73,365$ & $\$ 117,143$ & $\$ 190,508$ & $\$ 87,207$ & $\$ 277,715$ & $\$ 90,514$ & $\$ 368,229$ & $\$ 123,156$ & $\$ 491,385$ & $\$ 127,409$ & $\$ 618,794$ & $\$ 127,409$ & $\$ 746,203$ & $\$ 127,409$ & $\$ 873,612$ & $\$ 127,409$ & $\$ 1,001,021$ \\
\hline Non-Federal Share & & $\$ 0$ & $\$ 0$ & 50 & $\$ 178,823$ & $\$ 178,823$ & $\$ 219,222$ & $\$ 398,045$ & $\$ 160,040$ & $\$ 558,085$ & $\$ 12,269$ & $\$ 570,354$ & & $\$ 570,354$ & $\$ 127,867$ & $\$ 698,221$ & $\$ 127,867$ & $\$ 826,088$ & $\$ 127,867$ & $\$ 953,955$ & $\$ 127,867$ & $\$ 1,081,822$ \\
\hline \multirow{2}{*}{\multicolumn{23}{|c|}{$\begin{array}{l}\text { Total Planned } \\
\text { Actual Incurred Cost }\end{array}$}} \\
\hline & & & & & & & & & & & & & & & & & & & & & & \\
\hline Federal Share & $\$ 6,808$ & $\$ 6,808$ & $\$ 2,536$ & $\$ 9,344$ & $\$ 62,859$ & $\$ 73,365$ & $\$ 117,143$ & $\$ 190,508$ & $\$ 87,207$ & $\$ 277,715$ & $\$ 90,514$ & $\$ 368,229$ & $\$ 149,162$ & $\$ 517,391$ & & $\$ 517,391$ & & $\$ 517,391$ & & $\$ 517,391$ & & $\$ 517,391$ \\
\hline Non-Federal Share & $\$ 0$ & 50 & $\$ 0$ & \$0 & $\$ 178,823$ & $\$ 178,823$ & $\$ 219,222$ & $\$ 398,045$ & $\$ 160,040$ & $\$ 558,085$ & $\$ 223,162$ & $\$ 781,247$ & $\$ 180,636$ & $\$ 961,883$ & & $\$ 961,883$ & & $\$ 961,883$ & & 5961,883 & & $\$ 961,883$ \\
\hline Total Incurred Costs & $\$ 6,808$ & $\$ 6,808$ & $\$ 2,536$ & $\$ 9,344$ & \begin{tabular}{|l|l|}
241,683 \\
\end{tabular} & $\$ 252,188$ & $\$ 336,365$ & $\$ 588,553$ & $\$ 247,247$ & $\$ 835,800$ & $\$ 313,676$ & $\$ 1,149,476$ & $\$ 329,798$ & $\$ 1,479,274$ & & $\$ 1,479,274$ & & $\$ 1,479,274$ & & $\$ 1,479,274$ & & $\$ 1,479,274$ \\
\hline \multicolumn{23}{|l|}{ Variance } \\
\hline deral Share & 50 & 50 & so & 50 & s0 & so & s0 & 50 & 50 & 500 & so & & $-\$ 26,006$ & & & & & & & & & \\
\hline Non-Federal Share & 50 & $\$ 0$ & \$0 & $\$ 0$ & $\$ 0$ & $\$ 0$ & $\$ 0$ & $\$ 0$ & \$0 & $\$ 0$ & $-\$ 210,893$ & $-\$ 210,893$ & $-\$ 180,636$ & $-\$ 391,529$ & & & & & & & & \\
\hline Total Variance & $\$ 0$ & $\$ 0$ & \$0 & \$0 & $\$ 0$ & $\$ 0$ & $\$ 0$ & $\$ 0$ & \$0 & sol & $\mid$ & $-\$ 210,893$ & $-\$ 206,642$ & $-\$ 417,535$ & & & & & & & & \\
\hline
\end{tabular}

\section{References}

[1] Hine PJ, Davidson N, Duckett RA, Clarke AR, and Ward IM. Hydrostatically Extruded Glass-Fiber-Reinforced Polyoxymethylene. I: the Development of Fiber and Matrix Orientation, Polymer Composites, 1996, 17:720-9.

[2] Bay RS and Tucker III CL. Stereological Measurement and Error Estimates for Three-dimensional Fiber Orientation, Polymer Engineering and Science, 1992, 32:240-53.

[3] Bay RS and Tucker III CL. Fiber Orientation in Simple Injection Moldings. Part I: Theory and Numerical Methods, Polymer Composites, 1992, 13:317-31.

[4] Phelps JH. Process-Microstructure Models for Short- and Long- Fiber Thermoplastic Composites, Ph.D. Thesis, University of Illinois, UrbanaChampaign, 2009.

[5] Phelps JH and Tucker III CL 2009. An Anisotropic Rotary Diffusion Model for Fiber Orientation in Short- and Long-Fiber Thermoplastics,” Journal of the Non-Newtonian Fluid Mechanics, 156(3):165-176. 